DOI: $10.1515 / \mathrm{adms}-2017-0044$

\title{
L. Latka
}

Department of Materials Science, Strength and Welding, Mechanical Engineering Faculty, Wrocław University of Science and Technology, Wrocław, Poland leszek.latka@pwr.edu.pl

\section{THERMAL BARRIER COATINGS MANUFACTURED BY SUSPENSION PLASMA SPRAYING - A REVIEW}

\begin{abstract}
Thermal barrier coatings (TBC) is one of the most intensively studied of coatings' applications area. From 1970's $\mathrm{TBC}$ are developed in two independent ways: (i) development in new materials, with lower thermal conductivity, better erosion resistance and better thermal shock resistance or (ii) development in new deposition techniques. On this field besides conventional atmospheric plasma spraying (APS) and almost conventional (because of very common use) EB-PVD method, in the past 20 years two new techniques have been developed, namely suspension plasma spraying (SPS) and solution precursor plasma spraying (SPPS). In this paper only SPS method was described, as well as, new materials, which could be used in industrial applications of TBC. Moreover, the key issues, like suspension preparation, type of suspension injection, interaction between liquid droplets and plasma jet and deposition mechanism were described.
\end{abstract}

Keywords: suspension plasma spraying, thermal barrier coatings, microstructure, deposition mechanism, thermal conductivity

\section{INTRODUCTION}

Thermal barrier coatings (TBC) are used from almost 50 years to protect blades, especially in hot section, of gas turbines. This engines produce the energy from fuel and convert it into mechanical energy. The gas turbines are used mostly in aviation transport, but it could be found also in energy industry [1-3]. The main role of $\mathrm{TBC}$ is to protect metal substrate against high temperature and environmental conditions. Especially temperature of entering gases is important, because it depends on it the efficiency of gas turbine $[4,5]$. This dependence is clearly presented in Fig. 1. But the operating temperature now is in the board of melting point of materials, from which blades are done, there are mainly nickel-based superalloys, and it is more than $1500^{\circ} \mathrm{C}$ [6]. Moreover, there is a big problem with thermal shocks, when turbine starts and stops the temperature could jump from $0^{\circ} \mathrm{C}$ up to $1500^{\circ} \mathrm{C}$ in a very short time. This generates a big thermal stresses in the blades. It is a reason to very good protection of metallic elements by ceramic coatings. 


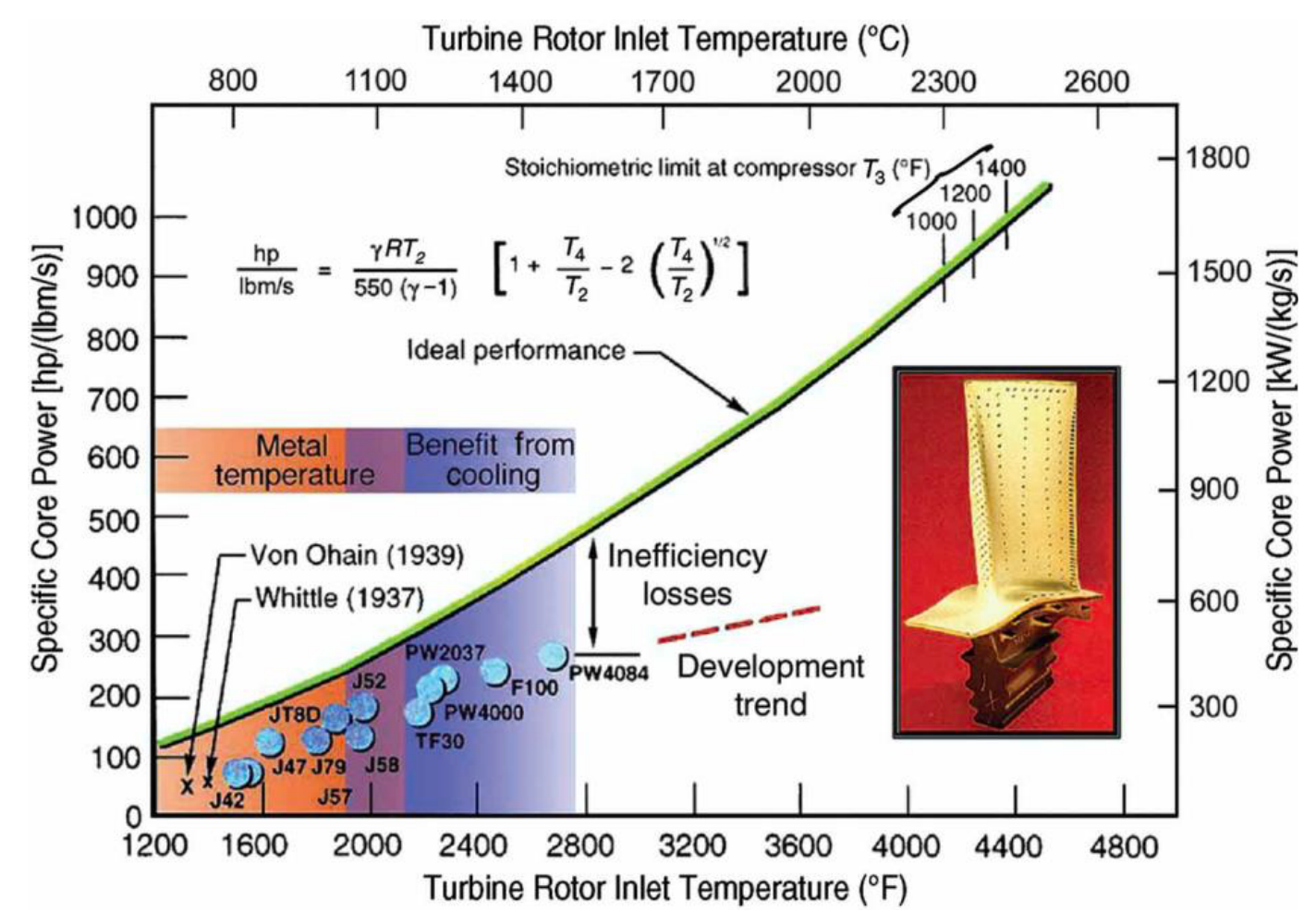

Fig. 1. The influence of turbine inlet temperature on the turbine core power and efficiency [5]

Thermal barrier coating is a complex system composed from three different layers: (i) ceramic top coat (TBC or TC), (ii) thermally grown oxides (TGO) and bond coat (BC) [7]. The scheme of TBC system with typical materials for each layer and its function is presented in Fig. 2. It needs to be highlighted that external ceramic coating is exposed for the most difficult conditions. There are very variable conditions of mechanical, thermal and chemical loads [8].

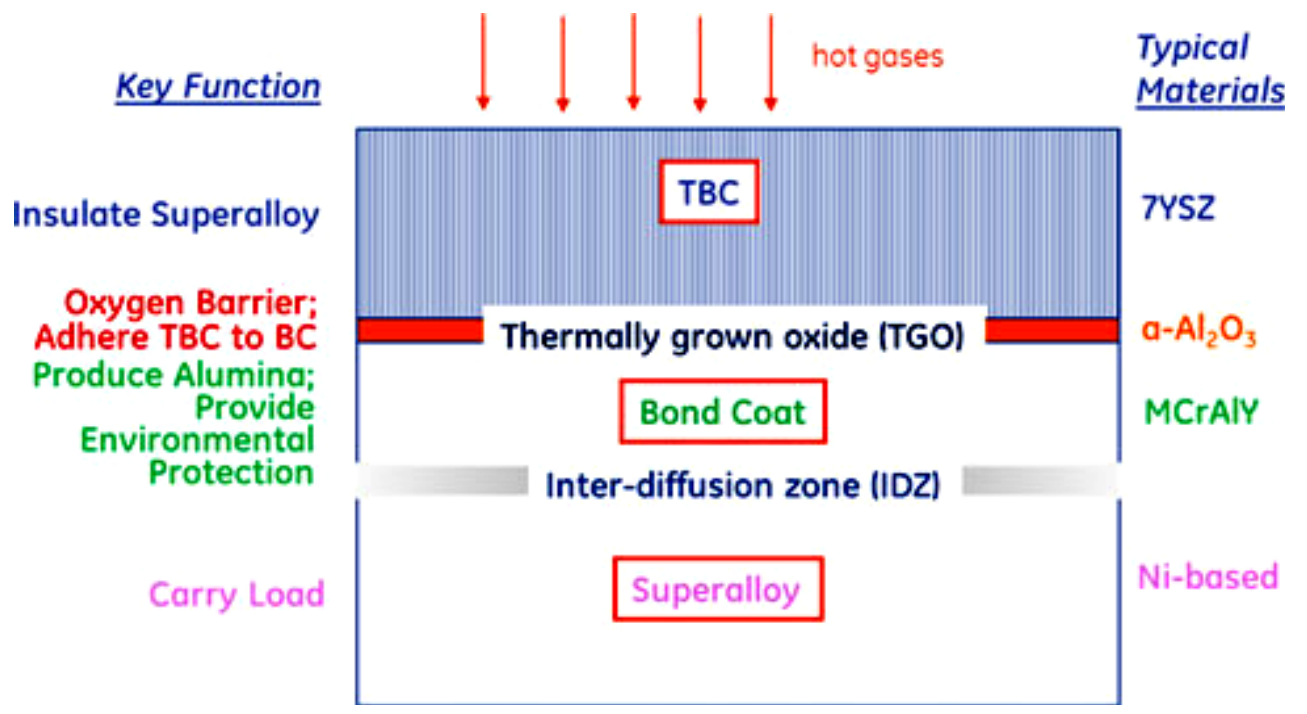

Fig. 2. Scheme of typical thermal barrier coating system [7] 
In the industry there are two main methods of coatings manufactured to obtain ceramic top coat in TBC system. One of them is electron beam physical vapor deposition (EB-PVD). In this technique a characteristic columnar microstructure could be obtained, which results in very high yielding strain tolerance, which occurs during thermal cycle changes. It is realized by voids between columns, which could open and close during thermal cycles. Moreover, such structure could reduced the thermal expansion mismatch between BC and TC [9-11]. But there are also some disadvantages of this method. First is a cost, it is the most expensive method of industry coatings manufactured and one of the most complicated. Second is linked to the structured and it is quite high value of thermal conductivity (the range from 1.8 up to $2.0 \mathrm{~W} / \mathrm{m} \cdot \mathrm{K}$, for YSZ) [12]. Scheme of columnar structure obtained by EB-PVD method is presented in Fig. 3a. It should be stressed that such type of microstructure promotes longer lifetime of TBC system [13].

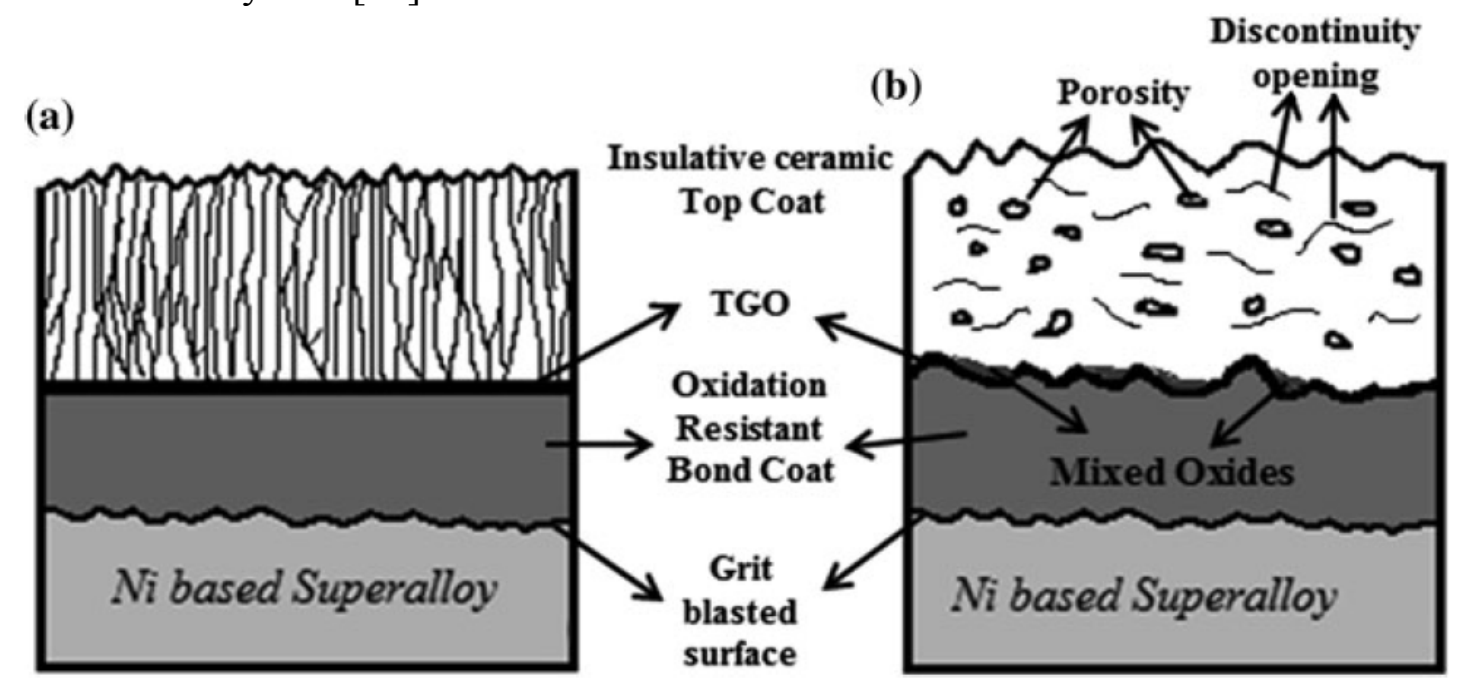

Fig. 3. Scheme of TBC structures obtained by: (a) EB-PVD and (b) APS [14]

Different microstructure, as well as, properties have coatings, which are manufactured by atmospheric plasma spraying (APS). This technique sometimes is called powder plasma spraying (PPS).It is used especially for less fragile elements because of much more lower cost of coatings' production $[15,16]$. In this technique the structure have horizontally situated lamellas with porosity and cracks, which are oriented perpendicular to the heat flow. Such type of structure, because of many gaps between splats results in lower value of thermal conductivity, even below $1.0 \mathrm{~W} / \mathrm{m} \cdot \mathrm{K}$ (for YSZ) [17]. Main disadvantage of APS technique is much lower thermal shock resistance in comparison to the EB-PVD [9]. Scheme of structure with horizontal splats with interlamellar gaps, which is characteristic for APS technique, is presented in Fig. 3b.

Generally summary of above mentioned issues is develop a new method, which allows to produce TBC top coats with low thermal conductivity, long lifetime, very good thermal shock resistance and will be relatively low cost. It should be a mixed of advantages of EB-PVD and APS techniques. This assumption could be realized by new method, which is modification of conventional plasma spraying, namely suspension plasma spraying (SPS). On the other hand new materials for ceramic top coat should be developed because of limited operating temperature of YSZ [18-20].

An improvement of coatings' properties could be reached by reducing grain size. It is well known, that nanosized crystal grains modified properties of materials and it was described like a Hall-Petch law [21]. Nanostructured coatings are produced by physical vapor 
deposition (PVD) or chemical vapor deposition (CVD), but they are time-consuming, as well as, cost-consuming methods. On the field of thermal spraying some attempts were made to use a coarse powder, which include nanosized crystal grains [22]. But during melting of nanograins a sintering of liquid phase take place and results in big grains growth, which change a structure from nano- to micro- one [23]. Some attempts used fine powder particles in conventional APS method did not work. It was caused because very low weight of particles and, as a consequence, low momentum to penetrate hot regions of plasma jet and low flow ability of dry nanometric and submicrometric powders [23, 24]. Another idea was to use nanostructured particles, which were agglomerated up to size of powder particles in APS technique (range from 10 to $100 \mu \mathrm{m}$ ) [25].

Completely different approach had a group of researches for Sherbrook University. They changed a transportation medium from gas to liquid phase [26]. Very fine powders particles are suspended in liquid phase, then formulate a big droplets, which have enough mass and momentum to penetrate hot regions of plasma jet. Moreover, transport of suspension is easier than transport of dry, coarse powder and liquid phase prevent fine powders from hot plasma. This new technique is called suspension plasma spraying (SPS) [26]. The particles size is from few up to hundered nanometers or sometimes it is up to few micrometers. Commonly a solid phase (quantity of powder in wt. \%) is in the range from 5 up to $40 \%$.

This method is intensively examined in very wide area, because of improved properties of obtained coatings in compare to their conventional (by APS) equivalents. Many examples of different applications of SPS technique could be found in [27-29]. But the most interesting area of new researches is issue of TBC and improvement of its properties. However, the SPS technique is more complex that APS method and requires much more preparation and attention, which will be given in detail below. There are also many process parameters, which are collected in Fig. 4.

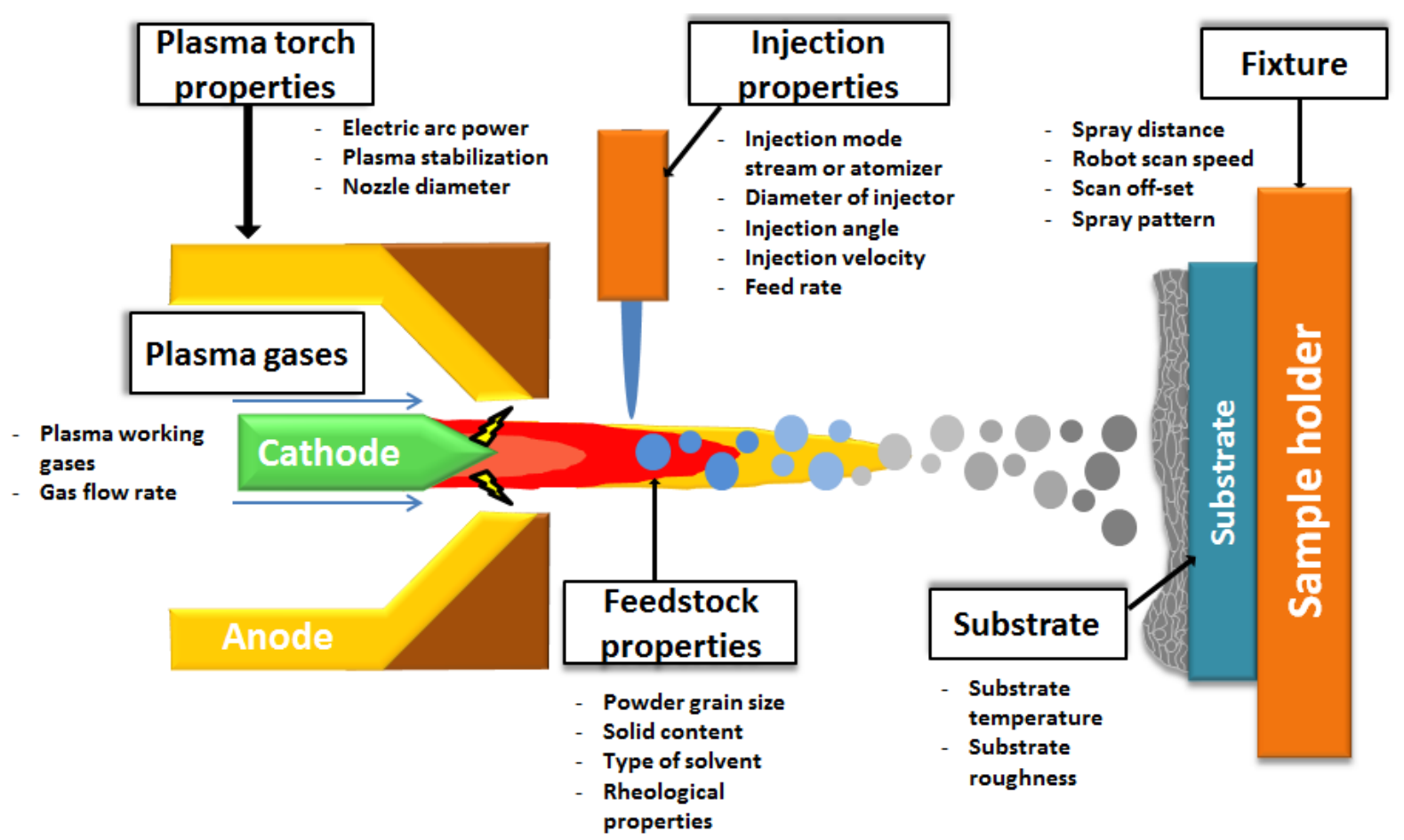

Fig. 4. Process parameters in SPS technique [30] 


\section{PREPARATION OF SUSPENSION}

At the very beginning it should be stressed that suspension preparation it is not only mixed of powder particles with liquid solvent. It is a complicated process, which is presented in Fig. 5. Very important issue is a solid content in suspension. Firstly it is connected with rheological properties of suspension, because viscosity of liquid feedstock strongly influences of droplet formulation in plasma jet. Moreover, the heat treatment of droplets in plasma jet is depend on its size. Besides quantity of solid particles in suspension droplets, as a consequence of amount of powder in hole suspension, strongly influences on microstructure of obtained coatings, especially on porosity, morphology and surface topography [31-34]. Of course size of powder particles is significantly lower than in APS process. Two main approaches to obtain such powders: bottom up and top down. In practice it is realized by mechanical milling or mechanical alloying, respectively. The main advantage of both method is low cost of production the nanostructured powders at low temperatures. Mechanical alloying seems to be much more useful in obtaining nanostructured materials instead of nanosized powders [3538]. Liquid phase (solvent) of suspension could be a distillated water, ethanol, methanol etc. The choice depend on surface tension and vaporization of liquid phase time in plasma jet. Many researches was carried out linked to influence of type of solvent. For example waterbased suspension droplets need almost three-times longer time to fully evaporated in plasma jet or faster fragmentation of suspension droplets was observed for ethanol-based one. Moreover, require velocity to good penetration of plasma jet is strongly depend on type of solvent [21, 39-41].

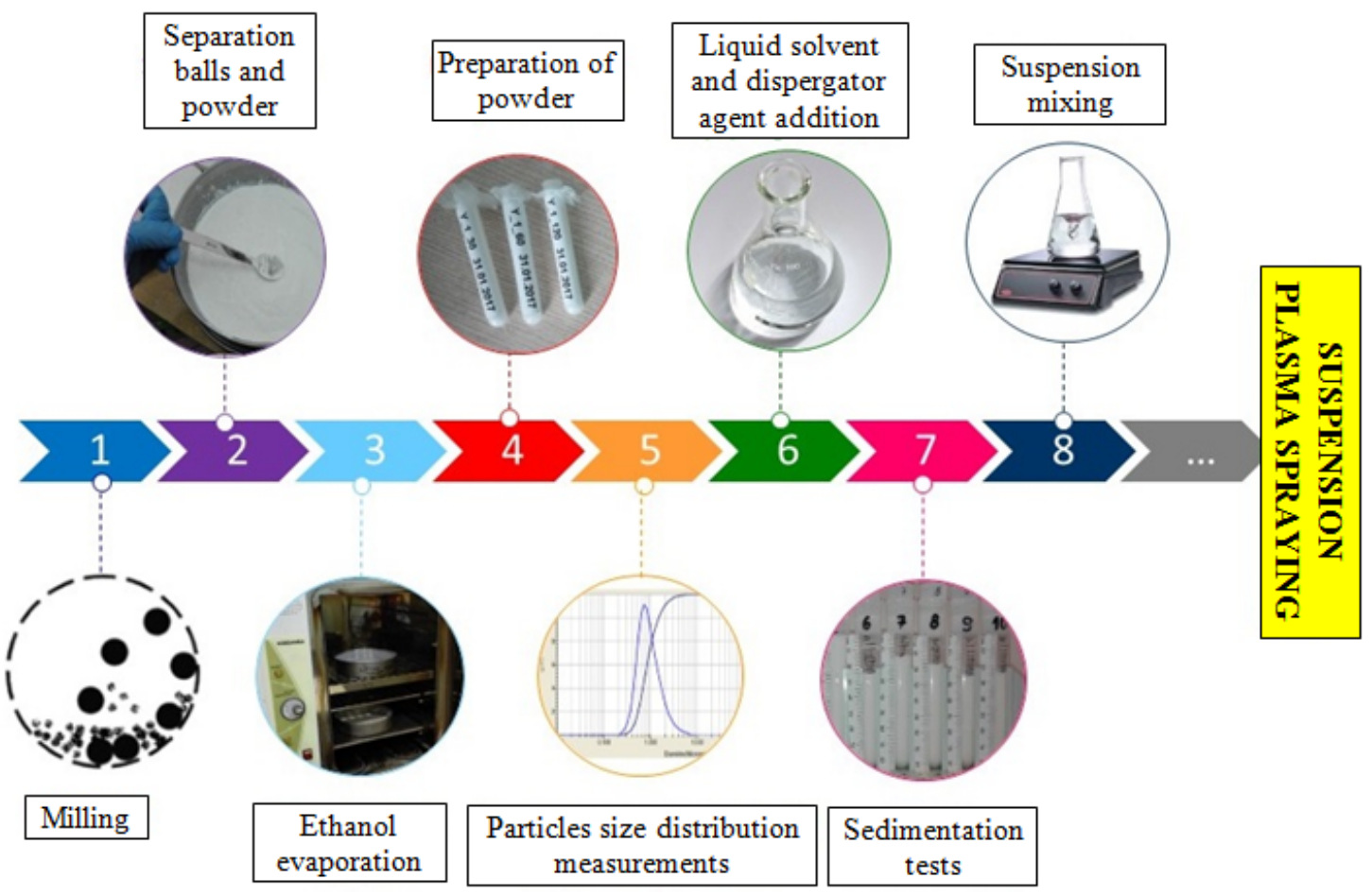

Fig. 5. Steps of suspension preparation for SPS [45]

One of the most important issue in SPS process is preparation stable suspension. The solid phase should be homogeneously distributed in solvent and they should not agglomerate. To improve suspension stability and prevent against agglomeration and sedimentation of fine 
particles some agents are added to suspension. Dispersant agents are added to change an electrical potential in solid particles by electrostatic and steric stabilization. Sedimentation is related with the suspension stability, particle size and its density. On the other hand the role of plasticizers is controlling of the suspension viscosity, because low viscosity is important to avoid the clogging and to drive suspension toward the injector [42-44].

Stability of suspension is described by zeta $(\zeta)$ potential. It is defined as a difference between electric potential of the particle's shear plane or shear Stern and the liquid beyond. The suspension is stable, when value of $\zeta$ is more than $+30 \mathrm{mV}$ or is less than $-30 \mathrm{mV}$. Stabilization of suspension is a result of higher repulsion between particles [46]. Besides zeta potential very important from a sedimentation point of view, is low shear viscosity. These two parameters should be controlled during suspension preparation very carefully [47].

\section{INJECTION OF SUSPENSION}

Transport of suspension from containers to the plasma torch is realized mainly in two ways: (i) pressure system of compressed air or (ii) peristaltic pumps, both are presented in Fig. 6. However, regardless on the type of suspension delivery system, it should provide a constant flow of slurry. The suspension injection influences on droplets formation and results in coatings' quality, so it is one of the key parameter in SPS process [21,30]. There are many possibilities and modes of suspension injection, depends on its type of injection, the angle or even place of injection. A briefly characteristic of different modes of suspension injection is given in Tab. 1.

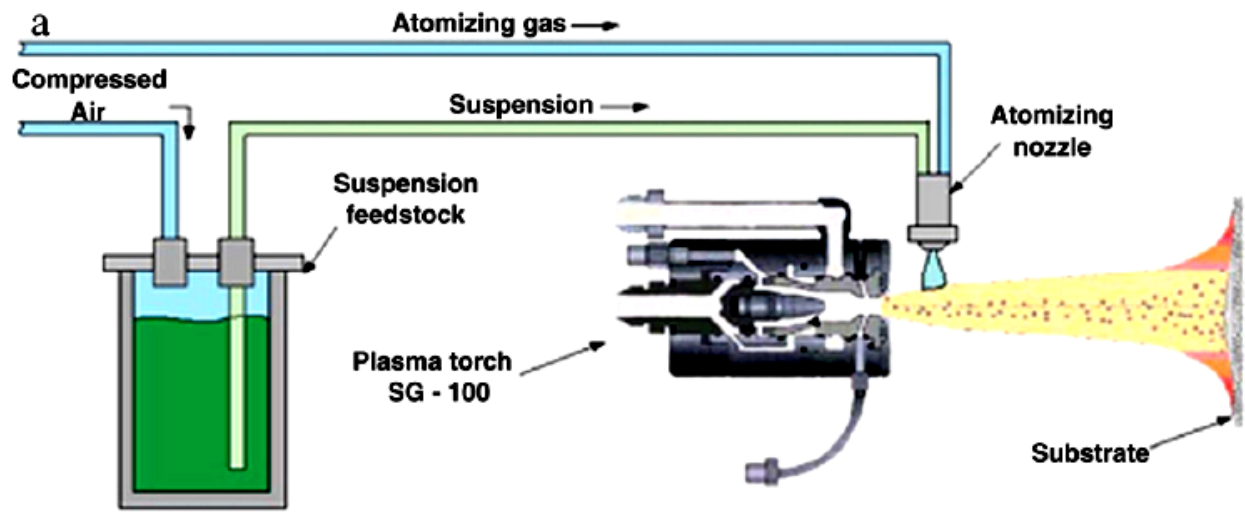

b

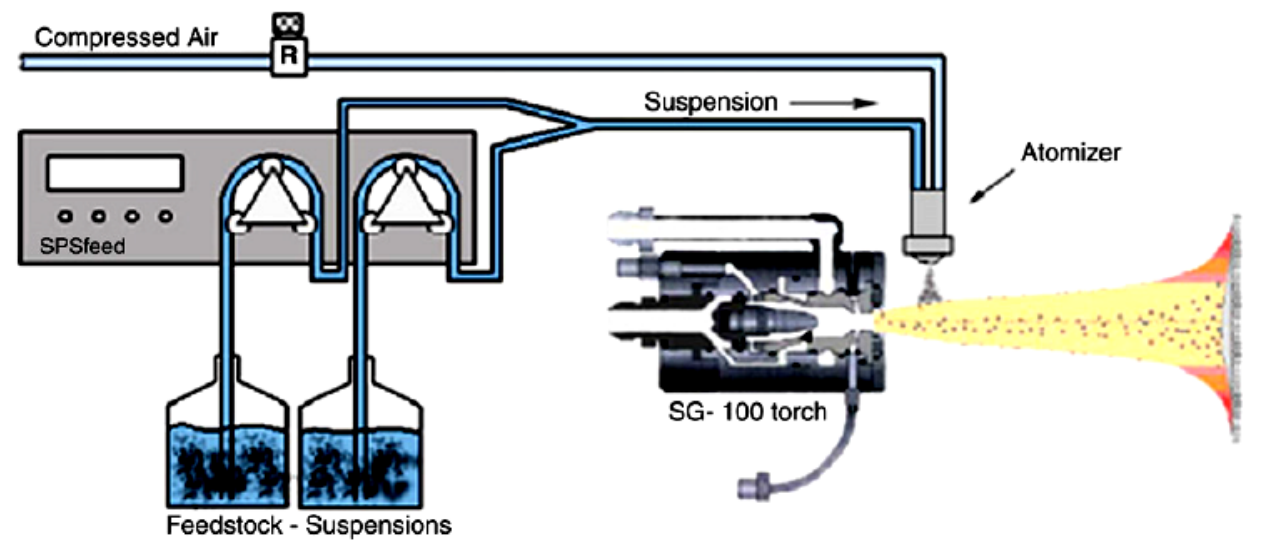

Fig. 6. Scheme of suspension delivery system in SPS: (a) pressurized vessel and (b) peristaltic pumps [21] 
Table 1. The comparison of different injection modes according to: (i) type of injection, (ii) angle of injection and (iii) place of injection [30]

\begin{tabular}{|c|c|}
\hline \multicolumn{2}{|c|}{ TYPE OF INJECTION } \\
\hline Continuous stream injection mode & Atomization injection mode \\
\hline $\begin{array}{l}\checkmark \text { injection with constant velocity and no } \\
\text { perturbation caused by atomization gases; } \\
\checkmark \text { possibility of changing of injection position; } \\
\checkmark \text { better penetration to the hot region of plasma } \\
\text { jet. }\end{array}$ & $\begin{array}{l}\checkmark \text { generation of small and uniform suspension } \\
\text { droplets, which results in fine splats formation; } \\
\checkmark \text { reduction of unmelted particles; } \\
\checkmark \text { possibility to limit clogging in injector and } \\
\text { prevent agglomeration in nozzle; } \\
\times \text { low penetration into hot region of plasma jet. }\end{array}$ \\
\hline \multicolumn{2}{|c|}{ ANGLE OF INJECTION } \\
\hline Radial injection mode & Axial injection mode \\
\hline \multicolumn{2}{|c|}{ is connected with construction of the torch } \\
\hline $\begin{array}{l}\checkmark \text { atomizer or continuous stream injection could } \\
\text { be used; } \\
\times \quad \text { needs precise selection of injection } \\
\text { parameters; } \\
\times \text { problems with clogging (less than in axial). }\end{array}$ & $\begin{array}{l}\checkmark \text { uniform heat treatment in plasma jet; } \\
\checkmark \text { fixed position of the injector; } \\
\times \text { problems with clogging. }\end{array}$ \\
\hline \multicolumn{2}{|c|}{ PLACE OF INJECTION } \\
\hline External injection mode & Internal injection mode \\
\hline $\begin{array}{l}\checkmark \text { possibility of feedstock injection at the very } \\
\text { beginning; } \\
\checkmark \text { lower inclination to nozzle clogging. }\end{array}$ & $\begin{array}{l}\checkmark \text { delivery suspension to the hot region of plasma } \\
\text { jet; } \\
\checkmark \text { limitation problems with instability of } \\
\text { injection. }\end{array}$ \\
\hline
\end{tabular}

\section{INTERACTION BETWEEN SUSPENSION AND PLASMA JET}

It is obvious, that interactions between suspension droplets and plasma jet are much more complex than in case of coarse powder in APS process. The influence of the liquid phase on the hot gas stream is enormous. During injection of suspension into the plasma jet, liquid is acted by inertia, viscosity and surface tension. Interaction between these forces are described by Reynolds number (Re) and Weber number (We). Generally, high values of Re and We promote a more rapid and finer atomization [48]. In the very beginning after suspension injection an aerodynamic breakup take place. It is a result of acting the aerodynamic forces. Then, liquid solvent evaporated in a very short time (because of high energy in plasma jet). Next, the sintering process of fine particles is beginning. It could be problematic, because of tendency to agglomeration of fine particles into a coarse ones (like in spray drying method). The time of sintering is strongly depends of temperature in the plasma jet [49]. After sintering almost immediately, melting of the sintered fine solids took place and they started to agglomerate. Then partially liquid material started to evaporate and at the end, molten (fully or partially) particles impact on the substrate $[22,48,50,51]$. As it was shown in Fig. 7 there are few types of particles (or droplets) to impact on the substrate (schematically marked from A to $\mathrm{E})$. 


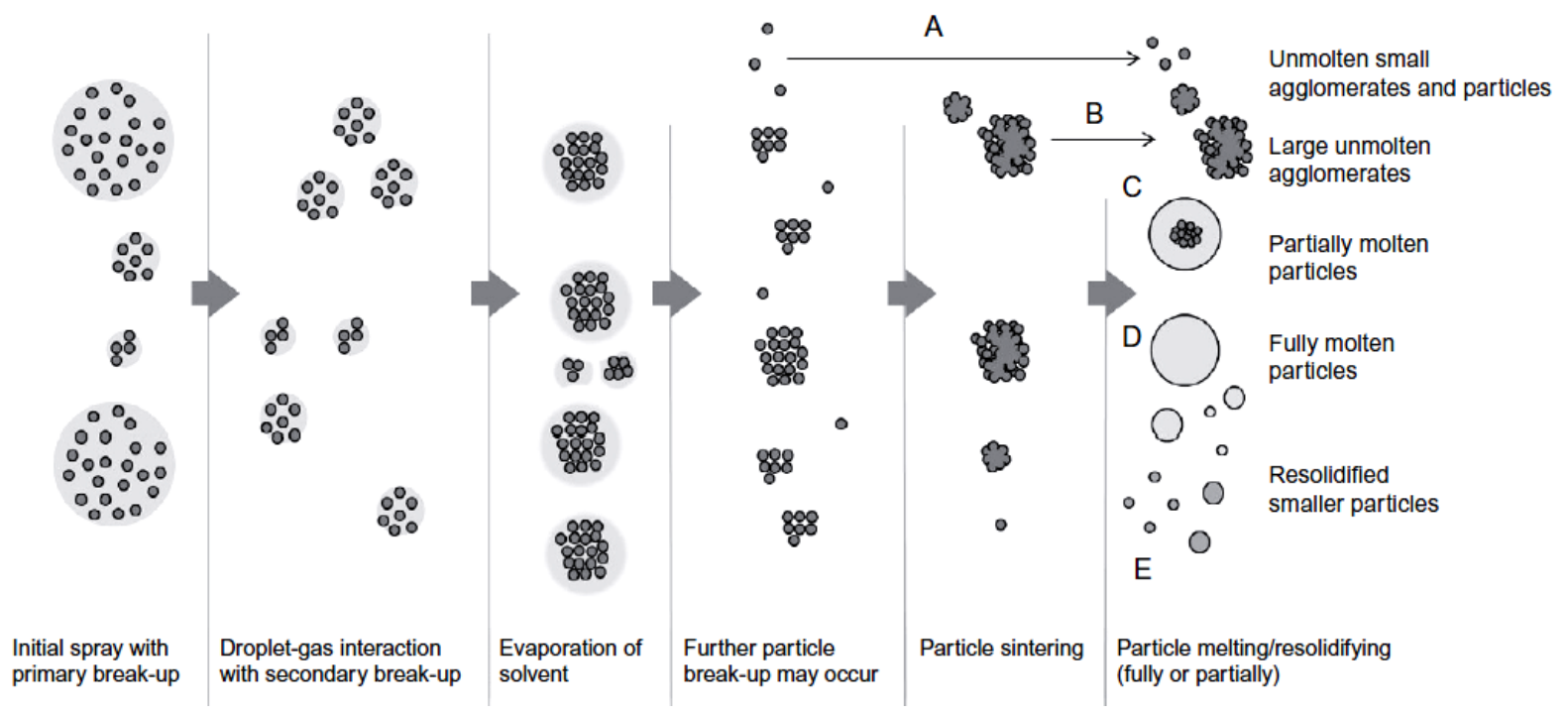

Fig. 7. Scheme of droplet formation process in SPS technique [48]

\section{MECHANISM OF COATINGS DEPOSITION IN SPS}

In SPS process of coatings manufacture there are many factors, which could strongly influence on deposition mechanism. It is caused by greater number of parameters than in APS process. Moreover, like it was described above, there are few types of thermally treated particles (molten, resolidified, unmolten etc.). But mostly in coatings produced by SPS could be found a characteristic two-zones microstructure [52]. Creation of such structure could be explained by different trajectories, on which different particles moved in the plasma jet. It is presented in Fig. 8. The sintering of small unmolten particles could take place after their deposition on the substrate. Because of short spray distance in SPS process much more heat is generated into the substrate. The major mechanism of coatings buildup is splashing well molten big particles and then its sintering during short time of solidification and cooling. The best description of the sintering during SPS process was found a model of surface diffusion $[53,54]$.

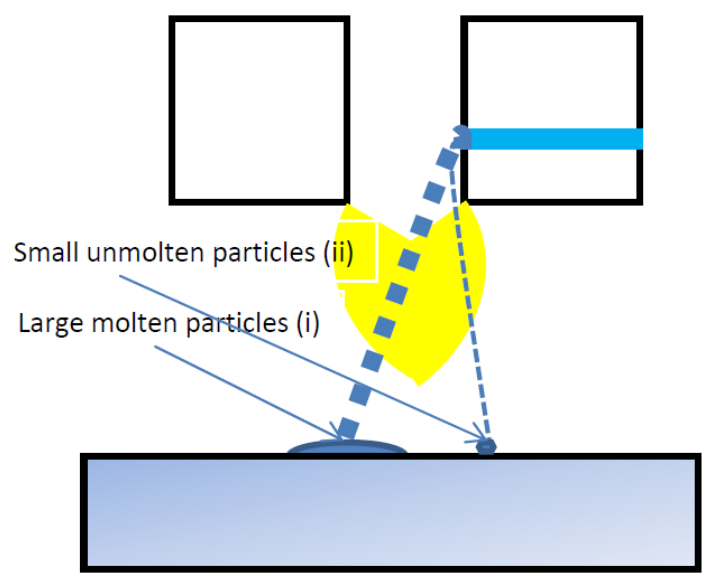

Fig. 8. Possible trajectories of droplets and/or particles in plasma jet during SPS with the use of internal continuous-stream injection mode [54] 
As a result of many researches is conclusion that by SPS process different mechanism of coatings buildup, as well as, different microstructures could be achieved. The main role played surface topography and roughness of substrate, however other parameters also influence on it. Moreover, type of solvent in suspension and solid content, as well as, injection mode results in different structure of the coatings [30, 31,34]. Coatings architecture is strongly dependent on initial roughness of the substrate. It could be found like a "shadow effect", which promotes growth of the coating in "columnar-like" mode [13, 29]. This type of structure is especially desirable in TBC applications because of better lifetime. But it was found, that columnar-like structure could be achieved also on flat substrates [55]. However, more important issue is relationship between two forces (Fig. 9): drag force ( $\left.F_{D}\right)$ and adhesion force $\left(\mathrm{F}_{\mathrm{A}}\right)$.

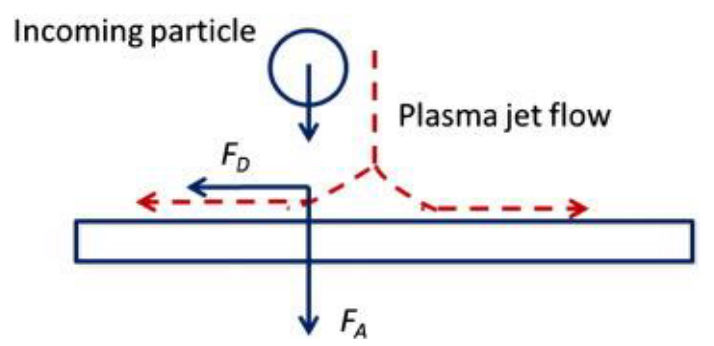

Fig. 9. Scheme of forces acting on an incoming particle [34]

Drag force pushed fine solid particles parallel to the substrate surface, whereas adhesion force caused adherence of particles to the substrate. In case of relatively big particles there is inequality $\mathrm{F}_{\mathrm{A}}>\mathrm{F}_{\mathrm{D}}$ because of its moving in the center region of plasma jet, which results of good heat treatment and fully molten. On the other hand, the small particles are moving on the periphery of plasma jet and in this case is inverse inequality $F_{D}>F_{A}$, which results in its moving parallel to the substrate surface. Then small, fully of partially molten particles adhere to the peaks of substrate roughness (Fig. 10). In this mechanism an important role also played a "shadowing effect" [34, 55, 56].

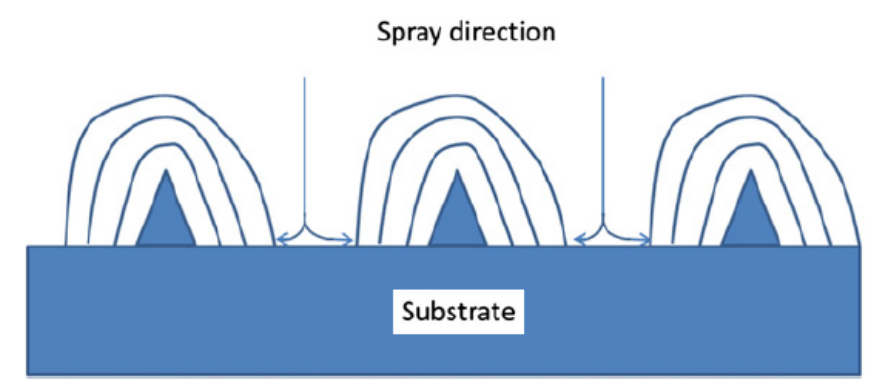

Fig. 10. Scheme of mechanism of the columnar-like structure formation in SPS on the roughened substrate $[13,34]$

In case of smooth substrate it is also a possibility to obtained a columnar-like structure of TBC coatings by SPS process. However it requires a low solid concentration in suspension. It is presented in Fig. 11. In the first step due to the single surface irregularities, single splats started to create a root of columns. Then, in second step, particles trajectories depend on the relations between $\mathrm{F}_{\mathrm{D}}$ and $\mathrm{F}_{\mathrm{A}}$ and it is similar to the case of roughened substrate. Third step is connected with growth of columns, which is supported by shadowing effect $[34,55]$. 

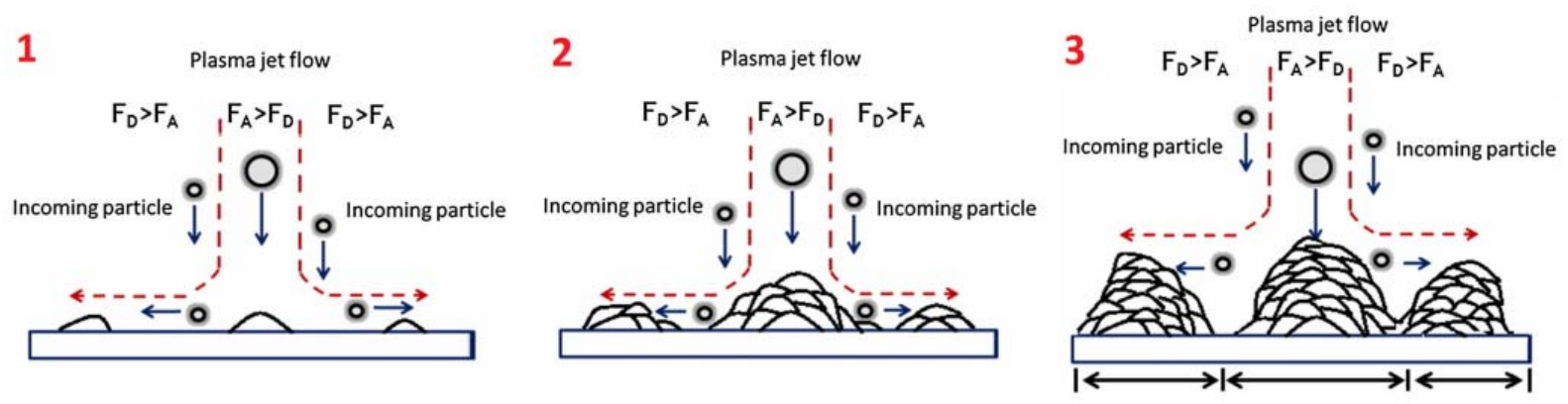

Fig. 11. Scheme of mechanism of the columnar-like structure formation in SPS on the smooth substrate [56]

Besides of different mechanisms of coatings' buildup and substrate topography, as well as, its roughness dependence, an important role play also type of torch and process parameters, like plasma gases composition and flow rate, solid content in suspension and its feed rate, an electrical power, spray distance etc. Different types of columnar-like structures in TBCs obtained by various types of plasma torch, sprayed with varied parameters were collected and presented in Figs. 12-14 (in all examples a coating's material is YSZ). It could be seen, that columns are very irregular, with relatively high width and its growth is not exactly perpendicular to the surface (except Axial III torch). On the other hand, in Fig. 13b structure is quite dense and such type of microstructure promotes this coating rather in application linked to the SOFC.

At the end of this point it should be stressed that deposition efficiency, which is extremely important in industry applications, is strongly correlated with such process parameters like solid content, solvent type, injection mode, type of the torch, chemical composition of the initial powder etc. [48].
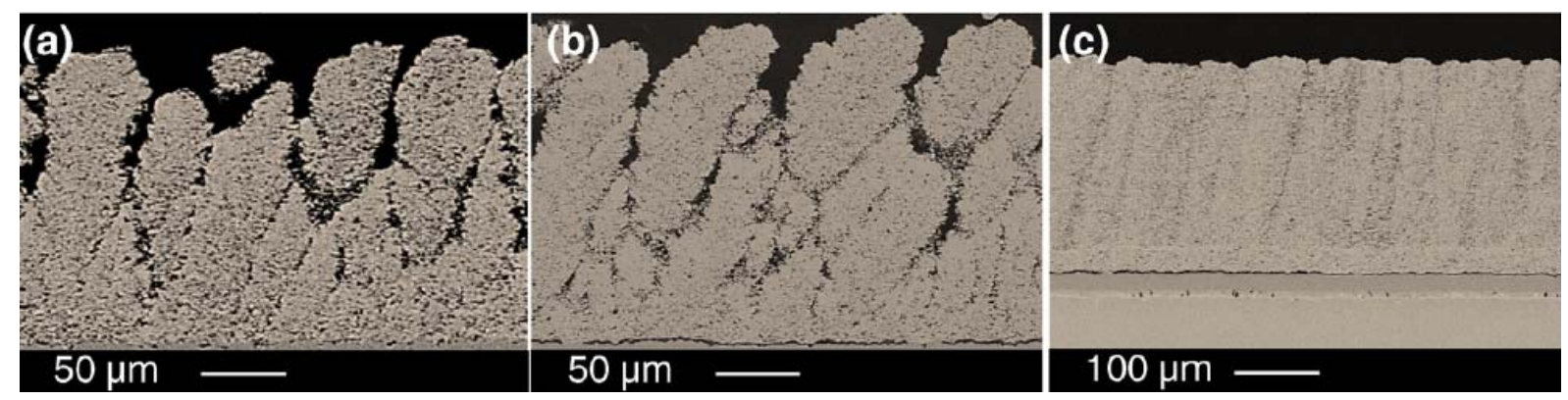

Fig. 12. Coatings' microstructures depend on SPS process parameters used of F4 VB low-power plasma torch with external radial injection [57]
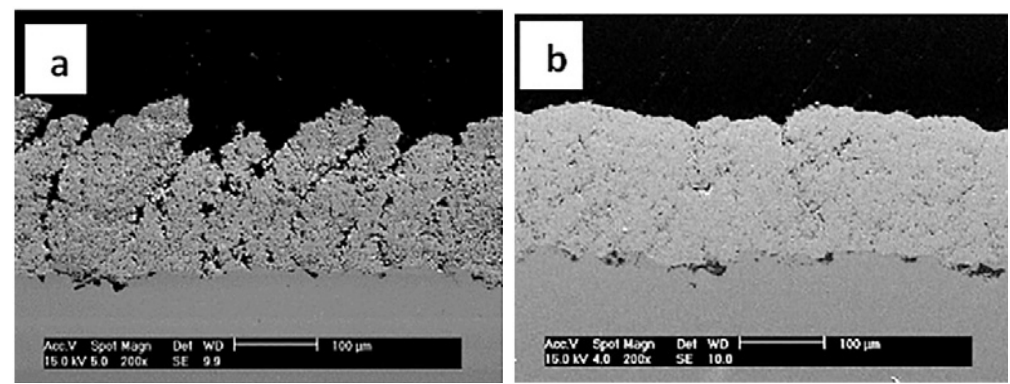

Fig. 13. Different coatings' microstructure depending on parameters of SPS process used of hWSP high-power plasma torch with external radial injection [58] 

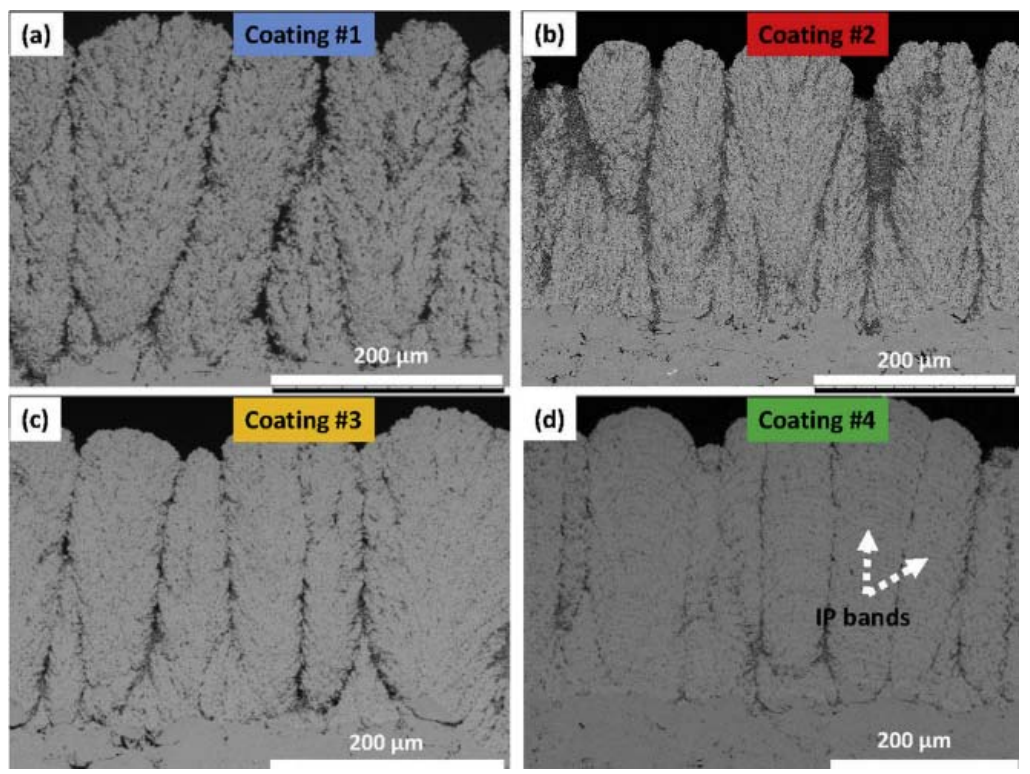

Fig. 14. Columnar-like microstructure with different process parameters obtained by SPS used of Axial III high-power plasma torch with internal axial injection [59]

\section{MECHANICAL AND THERMAL PROPERTIES OF SPS COATINGS}

The main mechanical property of each coating is its adhesion to the substrate. Until now, although different microstructures and nanometric crystal size, coating adhesion values in SPS technique is comparable with conventional APS method [48]. On the other hand, another mechanical properties, such microhardness and wear-resistance, are improved [60-63].

On the field of TBC, its mechanical properties, apart from adhesion, is mainly connected with microhardness, erosion resistance, fracture toughness and ballistic impact resistance. The values depend on chemical composition of based material, type of the torch and parameters of the SPS process. In some studies also a scratch test was used. It is a very good method to determine cohesion in the coating, according to ASTM G171-03 standard. For SPS coatings of zirconia stabilized yttria and yttria with ceria values of scratch hardness varied from 3 up to even $6 \mathrm{GPa}$, depending on process parameters [36, 64]. Microhardness values of YSZ coatings for TBC application produced by SPS technique varied form 6 up to $14 \mathrm{GPa}$, depending on torch type, particles size distribution and solid content in suspension $[65,66]$. Erosion resistance of TBC produced by SPS was found that the microstructure is a key factor, which strongly influences on erosion behavior. Density, grain and crystallite size could also influence on erosion resistance but in poorly way [67].

Properties of thermal transport, especially thermal conductivity, $\lambda_{\mathrm{T}}$, are strongly depend on type of coating's microstructure. To determine its value a following formula is needed:

$$
\lambda_{T}=\alpha_{T} \cdot c_{p} \cdot \frac{\rho_{\mathrm{m} n}}{1+3 \cdot \frac{\Delta L}{L}}
$$


where $\alpha_{T}$ is the thermal diffusivity, $c_{p}$ is the specific heat, $\rho_{300}$ is the apparent density in room temperature, includes coating's porosity and $\Delta L / L$ is thermal dilatation. The values of $\alpha_{T}$ are measured by LFA method [68]. On the other hand, the values of specific heat, density and thermal dilatation (all as a function of temperature) could be taken from materials base or they could be determine in additional tests. Experimental results confirmed the assumption about the dependence between coating's microstructure and its thermal conductivity. In case of YSZ coatings manufactured by SPS process with use of one cathode torch and radial injection mode, depend on many others parameters, the values of thermal conductivity at room temperatures were as follow: 0.69-0.97 [64], 0.47-0.86 [69], 0.70-1.25 [57] or 0.56 and 0.90 [70]. It was found, that YSZ coatings for TBC application produced via SPS exhibit relatively low thermal conductivity in high temperatures. For example in [71] thermal conductivity values were below $1 \mathrm{~W} / \mathrm{m} \cdot \mathrm{K}$ in the temperature range from $\mathrm{RT}$ up to $1100^{\circ} \mathrm{C}$. On the other hand, in case of axial injection mode at room temperature values of thermal conductivity are in the range from 0.5 to $0.8 \mathrm{~W} / \mathrm{m} \cdot \mathrm{K}$, but it was found in one coating even $0.3 \mathrm{~W} / \mathrm{m} \cdot \mathrm{K}$, what extremely low value for YSZ. For this coating thermal conductivity evolution up to $1200^{\circ} \mathrm{C}$ exhibit value around $0.6 \mathrm{~W} / \mathrm{m} \cdot \mathrm{K}[72]$.

In thermal cycle testing one regularity is visible - better thermal shock resistance is connected with columnar-like structure in the coating. Fan et al. [73] reported that for structure with relatively big gaps between "columns" the number of cycles in lifetime testing was more than 2 times higher than for others coatings. On the other hand, Zhai et al. [74] obtained lower number of thermal cycles for SPS coating than for nano-structured APS one in case of initial spallation. But for $10 \%$ of coating's spallation number of cycles was greater for SPS coating. Another investigations were carried out by Curry et al. [75]. They tested thermal shock resistance for different surface of bond coat treatment. The results showed slightly higher number of cycle for polished BC in compare to as-sprayed one. Grit blasted of BC and especially polishing and grit blasted, given significantly worse results.

\section{NEWS IN THE FIELD OF THERMAL BARRIER COATINGS}

As it was introduced, the efficiency of gas turbines is strongly depend on inlet temperature and its value still raising (according to Fig.1). New method of coatings manufacturing, suspension plasma spraying, only partially solved this problem. Although that microstructure is much finer than in conventional coatings, produced by APS, the functional properties, like thermal shock resistance and erosion resistance are not enough improved. On the other hand, it was found, that only thermal conductivity of coatings made by SPS have lower values than the ones produced by APS. Moreover, high density of vertical cracks is characteristic feature for these coatings. It results in increasing coating's strain tolerance. Additional, the unique types of microstructures could be obtained by SPS process, which are not available in APS method [48].

In industrial practice the most frequently used material for the top coat in TBCs is still YSZ. It is caused by its unique properties, like low thermal conductivity, good mechanical properties (especially toughness) and relatively high value of thermal expansion coefficient [76]. However, the maximum value of operating temperature for YSZ thermal barrier coatings is limited to $1200^{\circ} \mathrm{C}$ (for long term), because of phase transformation of zirconia in this temperature and sintering [9, 77-79]. In such case, there is a possibility in developing new materials for top coat in TBC systems. The requirements are presented in Fig. 15. The most important issue is of course low value of thermal conductivity, but significant role play also 
phase stability (no metastable phases), thermal shock resistance and mechanical fatigue resistance, which increase lifetime of TBC. Additional properties of new material for top coat of TBC system are sintering resistance and CMAS (calcium-magnesium-aluminum-silicon oxide system) resistance $[18,80]$.

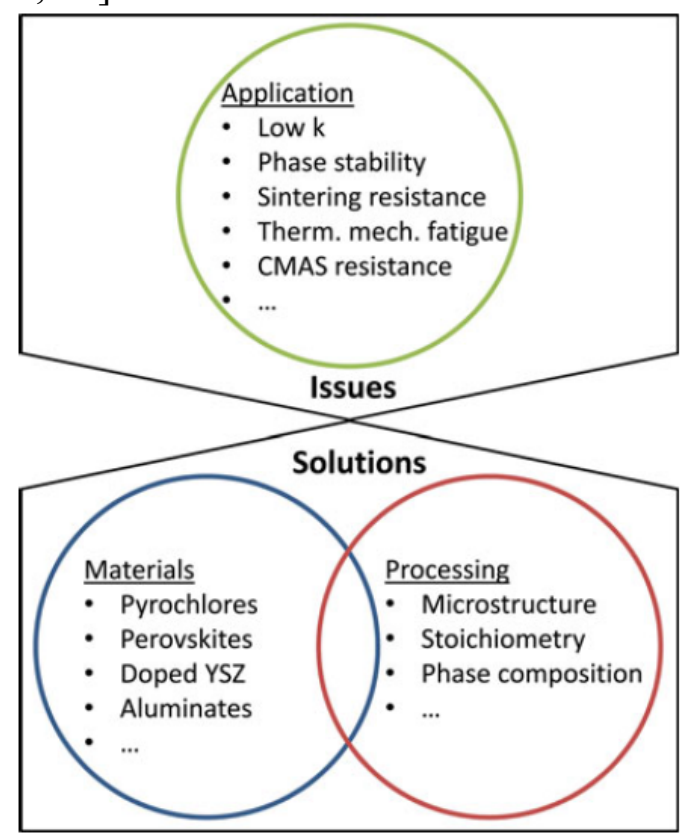

Fig. 15. The graph of requirements and proposed solutions in new generation of TBC [18]

Above mentioned requirements of ceramic top coat give some searching directions in new materials, which could be promised in such application. Cao et al. [81] made one of the first description of materials for thermal barrier coatings. They characterized the most popular replacement materials, such mullite, alumina, yttria with ceria stabilized zirconia, lanthanum zirconate and silicates. The main conclusion from these studies was that rare-earth oxides are promising materials for TBC's top coat [81]. Also the same conclusion could be found in [82]. $\mathrm{Wu}$ et al. tested a few rear-earth zirconates. They compare thermal conductivity at $700^{\circ} \mathrm{C}$ and possible maximum operating temperature (in short term). The results are very good, especially in case of $\mathrm{Gd}_{2} \mathrm{Zr}_{2} \mathrm{O}_{7}, \mathrm{Nd}_{2} \mathrm{Zr}_{2} \mathrm{O}_{7}$ and $\mathrm{Sm}_{2} \mathrm{Zr}_{2} \mathrm{O}_{7}$, which have lower values of thermal conductivity, similar thermal expansion coefficient and higher (even up to $2300^{\circ} \mathrm{C}$ ) short term operating temperature [82]. In another studies, made by Zhu and Miller [83], it was shown, that very promising issue is defect clustering, where $\mathrm{YSZ}$ was doped by an equal molar ratio of paired rare-earth oxides (in this study there were $\mathrm{Nd}_{2} \mathrm{O}_{3}-\mathrm{Yb}_{2} \mathrm{O}_{3}$ and $\mathrm{Gd}_{2} \mathrm{O}_{3}-\mathrm{Yb}_{2} \mathrm{O}_{3}$ ). Examinated coatings revealed lower thermal conductivity and better durability than baseline YSZ ones [83]. Similar rare-earth oxides used Gong et al. [84] with additional $\mathrm{Nd}_{2} \mathrm{O}_{3}-\mathrm{Gd}_{2} \mathrm{O}_{3}$, which all were sprayed by SPS. Some differenced in coatings' structures could be observed, doped coatings exhibit more porous microstructures with more numbers of voids. In case of thermal conductivity it was found that dopant of $\mathrm{Gd}_{2} \mathrm{O}_{3}-\mathrm{Yb}_{2} \mathrm{O}_{3}$ given the best results [84]. On the other hand Wang et al. [85] examinated nanocomposite lanthanum zirconate deposited by SPS like an alternatively material and structure for TBC application. The coatings have been successfully sprayed and XRD analysis confirmed that only single-phase of pyrochlore lanthanum zirconate was found. Moreover, in the coatings remains a full-nanosized structure with grain size were about $40 \mathrm{~nm}$ [85]. To improve lifetime of TBC top coats another idea was found, namely two-layer ceramic coating system [86]. The bottom layer is YSZ and top 
layer should be a material with phase stability in high temperature. Such types of materials are perovskite and pyrochlore [87]. Schematic view of such structure presented in Fig. 16.
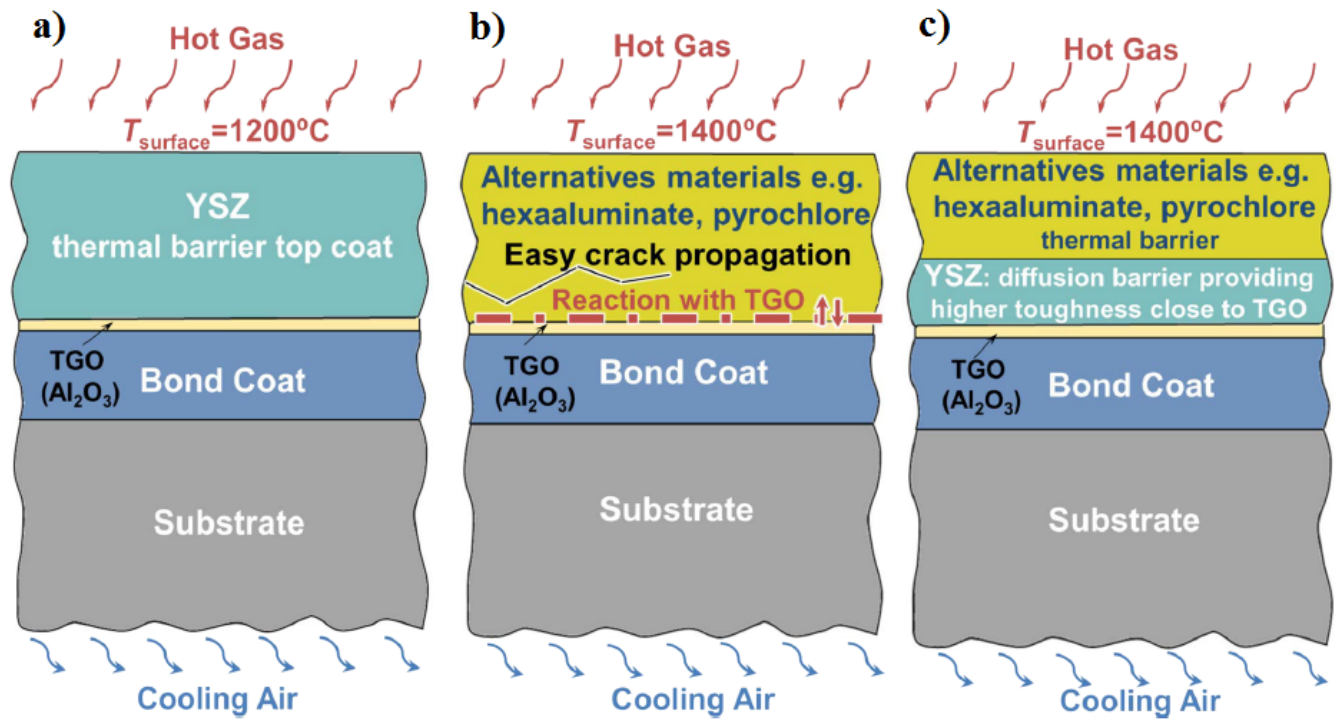

Fig. 16. Comparison between conventional single layer TBC (a) and single layer of alternatively material (b) with double layer TBC (c), which improve the possibility of working in higher operational temperature [87]

Intensive researches carried out by Mahade et al. [88, 89] concern double (DL) and triple layer (TL) thermal barrier coating systems. In DL they propose in ceramic top coat first layer as YSZ and second one from pyrochlore, in this case gadolinum zirconate (GZ). On the other hand in TL system the third one layer is made from dense GZ. The scheme of architectures of manufactured coatings are shown in Fig. 17. They tested thermal properties of both systems in compare to single layer YSZ. All coatings were made by SPS. First tests of thermal cyclic fatigue performed in $1100^{\circ} \mathrm{C}$ and $1200^{\circ} \mathrm{C}$. The results were better for DL and TL systems than one layer YSZ, but the differences were not significant. Also values of thermal conductivity are better for multilayer architectures than for YSZ [88]. In [89] Authors slightly changed spray parameters and raised temperature of thermal cyclic fatigue up to $1300^{\circ} \mathrm{C}$. The results of this test clearly shown that in temperatures higher than $1200^{\circ} \mathrm{C}$ coatings with external layer of YSZ have poorly thermal shock resistance. Number of cycles to failure was a few times higher for DL and TL systems than for YSZ single layer TBC. Values of thermal conductivity were slightly higher for TL than DL but it was considered, that dense layer of GZ should improves CMAS and erosion resistance [89].

Single Layer TBC

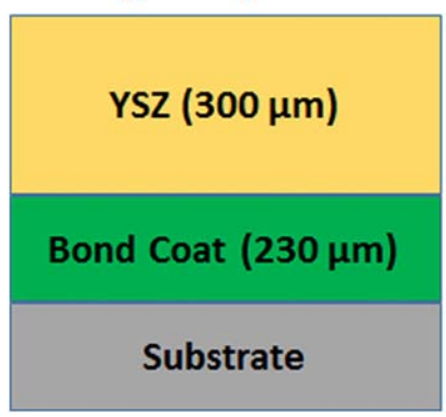

Double Layer TBC

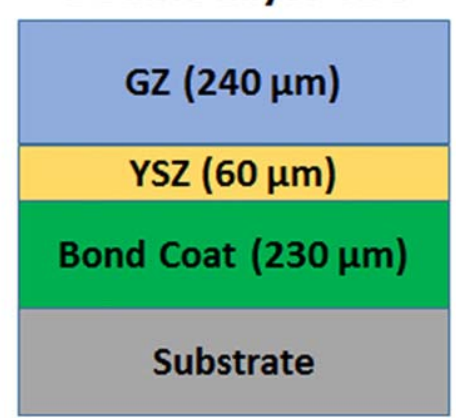

Triple Layer TBC

\begin{tabular}{|c|}
\hline Dense GZ $(40 \mu \mathrm{m})$ \\
\hline GZ $(200 \mu \mathrm{m})$ \\
\hline YSZ $(60 \mu \mathrm{m})$ \\
\hline Bond Coat $(230 \mu \mathrm{m})$ \\
\hline Substrate \\
\hline
\end{tabular}


Fig. 17. Scheme of single- or multi-layered TBC manufactured by SPS [89]

Double layer system was also investigated by Schlegel et al. [90]. However, they used as the top layer another material, rare-earth complex perovskite $\mathrm{La}\left(\mathrm{Al}_{1 / 4} \mathrm{Mg}_{1 / 2} \mathrm{Ta}_{1 / 4}\right) \mathrm{O} 3$ (LAMT). This material has relatively low thermal conductivity and good CMAS resistance. Results of thermal cycling test shown significant increase of lifetime double layer system in compare to single layer. It should be stressed that these tests carried out at $1390^{\circ} \mathrm{C}$, so out of the range of YSZ coating [90]. Different approach had Wang et al. [91]. In their studies they used pyrochlore lanthanum zirconate (LZ) and YSZ. Authors produced optimized functionally graded coating (OFGC) as a mixture of two ceramics. Additional they manufactured single ceramic layer coating (SCLC) with LZ and double ceramic layer coating (DCLC) with top from LZ and below YSZ layer. All coatings produced by SPS process. The thermal shock resistance (in $1000^{\circ} \mathrm{C}$ and $1200^{\circ} \mathrm{C}$ ) was significantly better for OFGC (Fig. 18). Moreover, functionally graded architecture of coating allows to reduce thermal mismatch which appears between two ceramic [91].
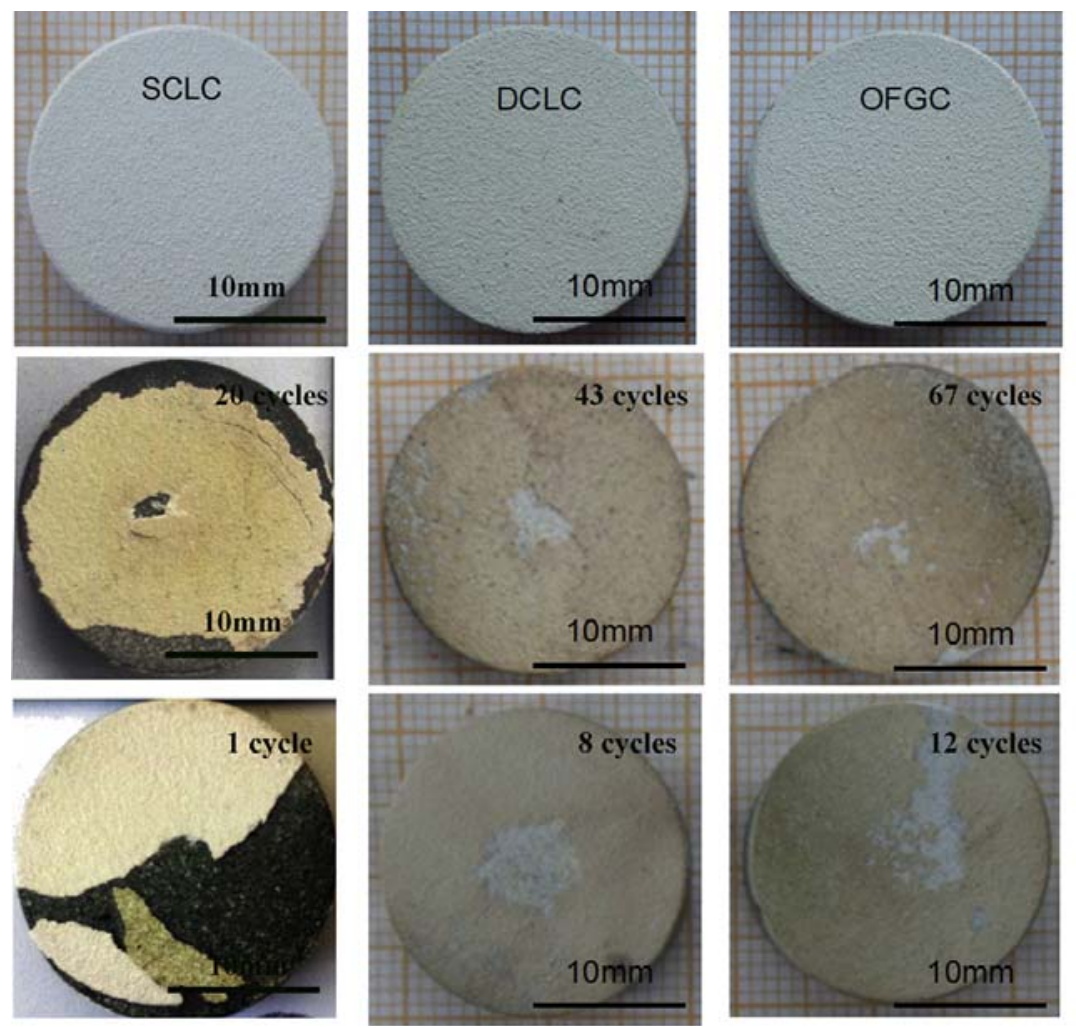

as-sprayed

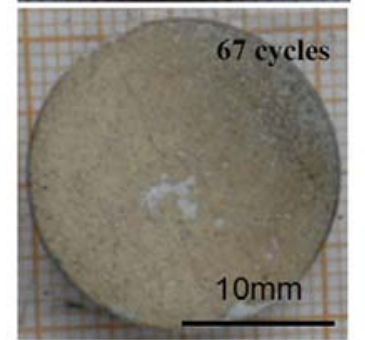

after $1000^{\circ} \mathrm{C}$

thermal shock

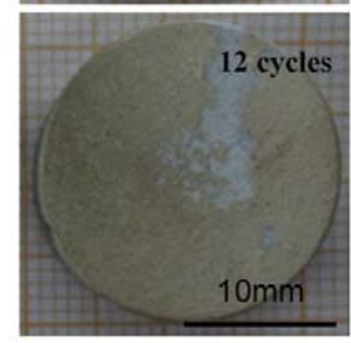

after $1200^{\circ} \mathrm{C}$

thermal shock

Fig. 18. Comparison of different types of TBC after thermal cycling tests [91]

New trends of TBC researches are connected with developing of multilayer systems, as well as, functionally graded ones. On this field interesting preliminary studies done in [92]. Authors introduced three layer system with YSZ on the bottom, gadolinium zirconate low thermal conductivity layer in the middle and two version of top layer, which should have better CMAS and erosion resistance than dense GZ. In one case it is an yttria layer and second case is yttrium aluminum garnet (YAG) layer [92]. Scheme of this multi layer systems is presented in Fig. 19. Unfortunately, in this studies there was no information about thermal shock, CMAS and erosion resistance, as well as, thermal conductivity of such systems. 


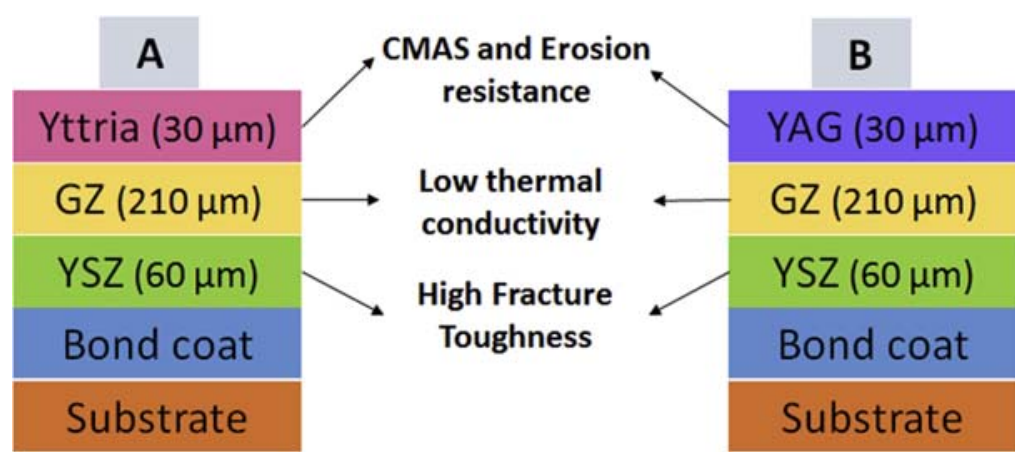

Fig. 19. Scheme of multi-layered architecture of TBC with functions of each layer: (a) with yttria top layer and (b) with yttria aluminum garner [92]

On the other hand developing on the field of YSZ as a top coat material in TBC system is still visible, but produced like multilayered or functionally grade. Interesting researches were made by Carpio et al. [93], in which multilayered and functionally-graded structures of YSZ were compared due to different CMAS resistance. The architectures of tested systems are shown in Fig. 20. The results confirmed that nanometric structure of the top in multi-layered coating more successfully blocking CMAS-1 penetration. Slightly better results achieved for both functionally-graded coatings. In case of CMAS-2, which was more aggressive, both multi-layered coatings were damaged. Functionally-graded ones had better resistance. However, G1 (with nanostructured layer on the top) exhibits higher penetration depth of CMAS-2 than in case of G2 layer (with micrometric structure) [93].

M1

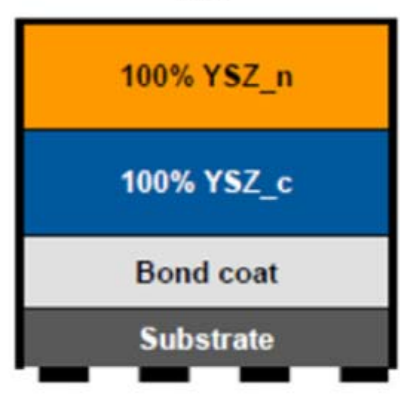

M2

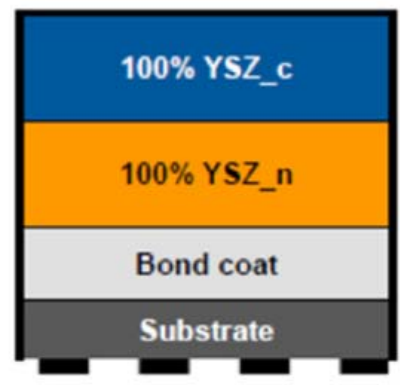

G1

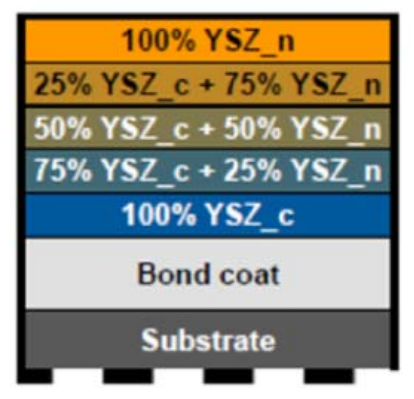

G2

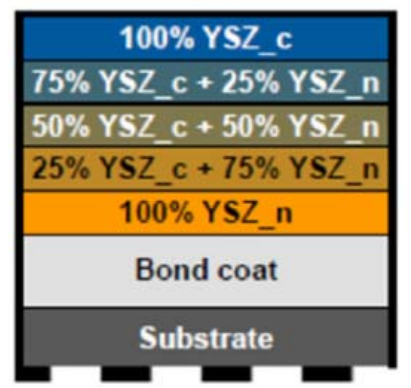

Fig. 20. Scheme of different architectures of TBC ( $M$ - multilayer coatings, $G$ - functionally graded coatings, C - conventional feedstock, $\mathrm{n}$ - nanostructured feedstock) [93] 
New develops on the field of thermal barrier coatings are: (i) new materials, which are used like a replacement of yttria stabilized zirconia, (ii) different coating's architecture, ex. Multi-layered or functionally-graded and (iii) new technologies, which allow obtained finely grained microstructures. The last one issue concerns suspension plasma spraying and solution precursor plasma spraying. In this article only SPS method was described, nevertheless SPPS process is also intensively studied and developed. The reasons of searching new solutions are following: lower thermal conductivity because of higher operating temperatures of turbines, longer lifetime and better thermal shock resistance, lower tendency to sintering at high temperature, better CMAS and erosion resistance and last but not the least - production costs. It should be stressed that in SPS process a fundamental role plays suspension preparation and its properties. It is a critical point in whole process and the depth researches should be done on the fields of colloidal chemistry and rheology. Suspensions should be well-dispersed, stable and easily in storage. Moreover, the phenomena characteristic for SPS are still not well understand. An advanced method of diagnostic should be implemented for get to know dependencies between them and process details. On the other hand, a numerical modeling, especially a dynamic one, is more often used in SPS process descriptions. Among all these issues, SPS method seems to be a promising technology of the TBC's top coat manufacturing. According to Fig. 21, it could be seen, that SPS is a multi-factor compromise method between EB-PVD and APS techniques. Presented features of SPS technique are still in develop state, so they may be improved. Very important issue is that it is possible to join APS and SPS methods in one set-up, changing only feeding system.
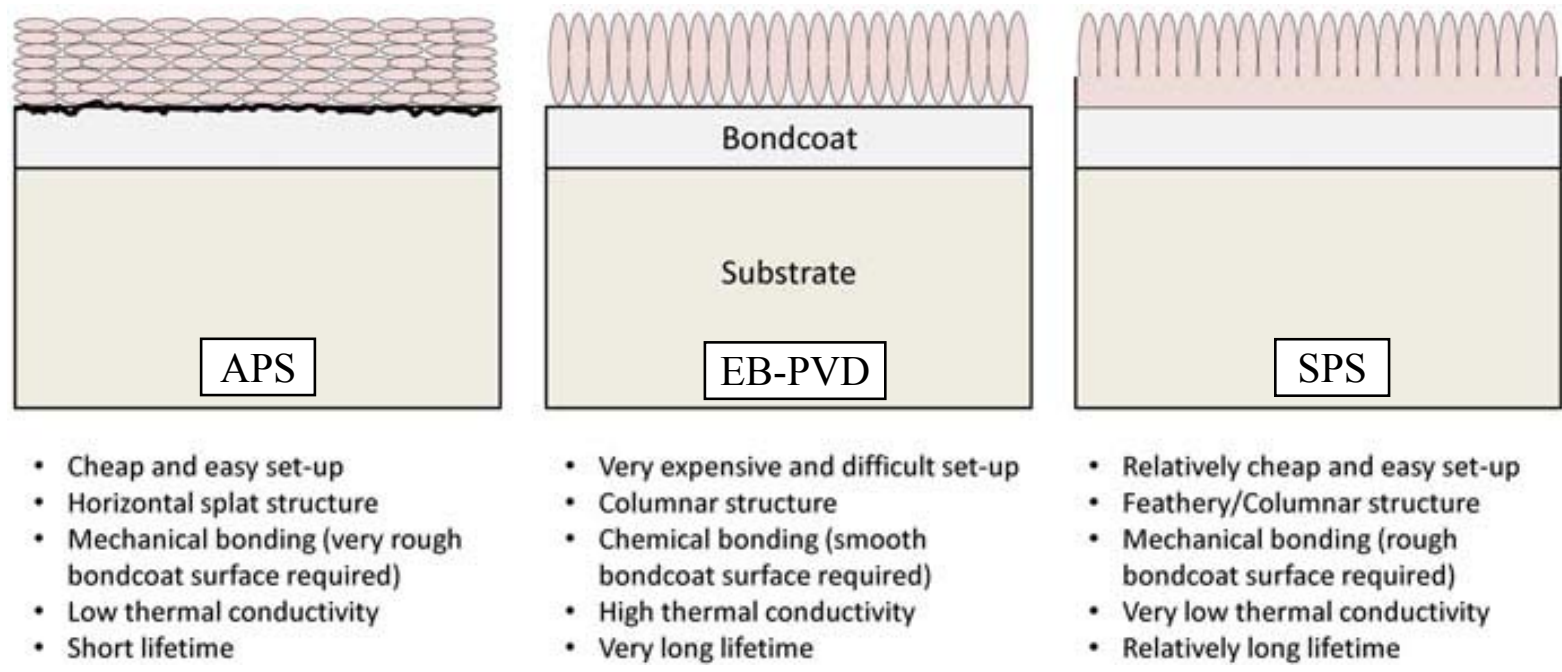

Fig. 21. Schematic comparison of structures obtained by APS, EB-PVD and SPS methods and their characteristics [76]

Current trend in top coat's microstructure is manufacturing of columnar-like one. But, depending on process parameters different types of columns could be achieved. The three main types of the columnar-like structures collected in Fig. 22. The fundamental differences between them concern with thermal conductivity values (the lowest for type 1 and it raises up for type 2 and more for type 3) and contrary for strain tolerance (the best for type 3 and it getting worse for type 2 and more for type 1 ). 


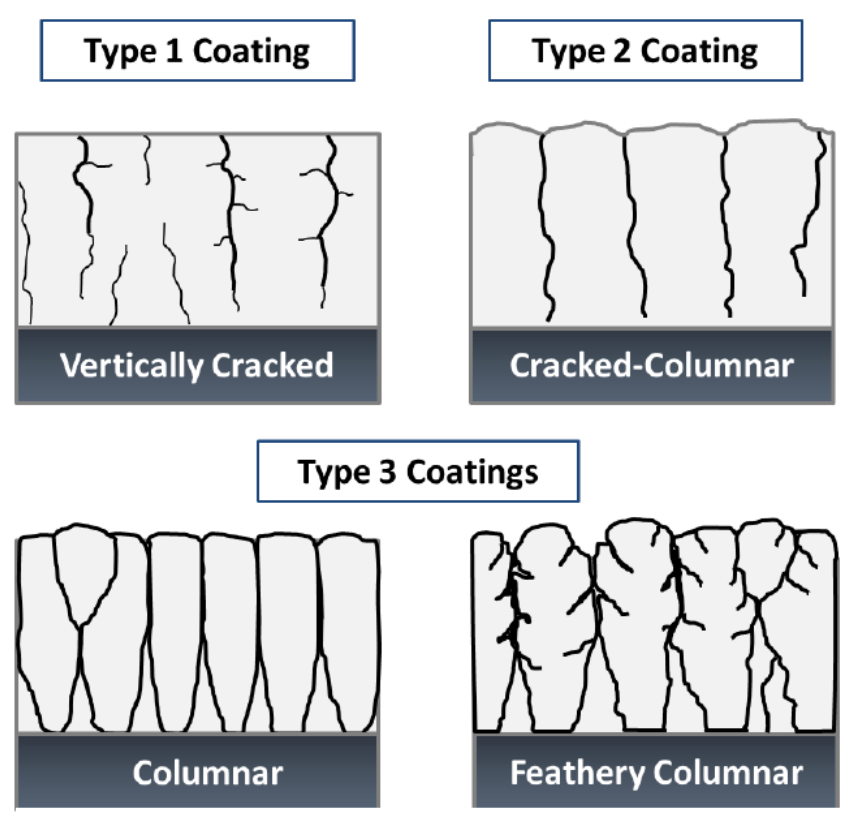

Fig. 22. Scheme of different types of TBC manufactured by SPS [94]

The main conclusions from a huge number of researches concern TBC ceramic top coatings are following:

- fine microstructure (even nanosized) with high value of porosity but small size and often spherical ones provide very low value of thermal conductivity;

- choosing the properly SPS process parameters it is possible to obtained columnar-like structures in ceramic coatings;

- coatings produced by SPS have improved thermal shock resistance in compare to the ones obtained by APS.

Nevertheless, regular columnar structure similar to the one, which is achieved by EBPVD method is not possible to obtain with use of suspension plasma spraying. The main explanation of this fact is a comparison of particles size used in SPS method with single atoms and/or molecules used in EB-PVD. This small molecules formed fundamental, called "islands", on which very narrow and regular columns building-up.

\section{REFERENCES}

1. Greatrix D.R., Powered Flight, Springer, London, 2012.

2. Simoes-Moreira J.R., Fundamentals of thermodynamics applied to thermal power plants [in] Thermal power plant performance analysis, G.F.M. de Souza [ed.], Springer, London, 2012.

3. Padture N.P., Gell M., Jordan E.H., Thermal barrier coatings for gas-turbine engine applications, Science 296 (2002) 280-284.

4. Krause A.R., Garces H.F., Dwidevi G., Ortiz A.L., Sampath S., Padture N.P., Calcia-magnesiaalumino- silicate (CMAS) - induced degradation and failure of air plasma sprayed yttria stabilized zirconia thermal barrier coatings, Acta Materialia, 105 (2016) 355-366.

5. Dimiduk D.M., Perepezko J.H., Mo-Si-B alloys: developing a revolutionary turbine engine material, MRS Bulletin 28 (2003) 639-645. 
6. Clarke D.R., Oechsner M., Padture N.P., Thermal barrier coatings for more efficient gas turbine engines, MRS Bulletin 37 (2012) 891-898.

7. Hardwicke C.U., Lau Y.-C., Advances in thermal spray coatings for gas turbines and energy generation: a review, Journal of Thermal Spray Technology 22 (2013) 564-576.

8. Sadowski T., Golewski P., Loadings in thermal barrier coatings of jet engine turbine blades - an experimental research and numerical modeling, Springer, London, 2016.

9. Guignard A., Development of thermal spray processes with liquid feedstocks, Forschungszentrum Julich, 2012.

10. Darolia R., Thermal barrier coatings technology: critical review, progress update, remaining challenges and prospects, International Materials Review 58 (2013) 315-348.

11. Schulz U., Schmucker M., Microstructure of $\mathrm{ZrO}_{2}$ thermal barrier coatings applied by EB-PVD, Materials Science and Engineering: A 276 (2000) 1-8.

12. Schulz U., Saruhan B., Fritscher K, Leyens C., Review on advanced EB-PVD ceramic topcoats for TBC applications, International Journal of Applied Ceramic Technology 1 (2004) 302-315.

13. VanEvery K., Krane M.J.M., Trice R.W., Wang H., Porter W., Besser M., Sordelet D., Ilavsky J., Almer J., Column formation in suspension plasma sprayed coatings and resultant thermal properties, Journal of Thermal Spray Technology 20 (2011) 817-828.

14. Karaoglanli A.C., Doleker K.M., Ozgurluk Y., State of the art thermal barrier coating (TBC) materials and TBC failure mechanism [in] Properties and characterization of modern materials, A. Oschner and H. Altenbach [eds.], Springer, Singapore, 2017.

15. Miller R.A., Current status of thermal barrier coatings - an overview, Surface and Coatings Technology 30 (1987) 1-11.

16. Miller R.A., Thermal barrier coatings for aircraft engines: history and directions, Journal of Thermal Spray Technology 6 (1997) 35-42.

17. Mauer G., Vassen R., Stoever D., Atmospheric plasma spraying of yttria-stabilized zirconia coatings with specific porosity, Surface and Coatings Technology 204 (2009) 172-179.

18. Vassen R., Jarligo M.O., Steinke T., Mack D.E., Stoever D., Overview on advanced thermal barrier coatings, Surface and Coatings Technology 205 (2010) 938-942.

19. Clarke D.R., Phillpot S.R., Thermal barrier coating materials, Materials Today 8 (2005) 22-29.

20. 20.Stoever D., Pracht G., Lehmann H., Dietrich M., Doering J., Vassen R., New material concepts for next generation of plasma-sprayed thermal barrier coatings, Journal of Thermal Spray Technology 13 (2004) 76-83.

21. Pawłowski L., Finely grained nanometric and submicrometric coatings bythermal spraying: a review, Surface and Coatings Technology 202 (2008) 4318-4328.

22. Pawłowski L., Suspension and solution thermal spray coatings, Surface and Coatings Technology 203 (2009) 2807-2829.

23. Pawłowski L., The science and engineering of thermal spray coatings, $2^{\text {nd }}$ ed., Wiley, Chichester, 2008.

24. Fauchais P., Montavon G., Bertrand G., From powders to thermally sprayed coatings, Journal of Thermal Spray Technology 19 (2009) 56-80.

25. Lima R.S., Marple B.R., Thermal spray coatings engineered from nanostructured ceramic agglomerated powders for structural, thermal barrier and biomedical applications: a review, Journal of Thermal Spray Technology 16 (2007) 40-63.

26. Gitzhofer F., Bouyer E., Boulos M.I., Suspension plasma spray, US5609921 A, 1997. 
27. Vassen R., Kassner H., Mauer G., Stoever D., Suspension plasma spraying: process characteristics and applications, Journal of Thermal Spray Technology 19 (2010) 219-225.

28. Fauchais P., Vardelle M., Vardelle A., Goutier S., What do we know, what are the current limitations of suspension plasma spraying? Journal of Thermal Spray Technology 24 (2015) 1120-1129.

29. Fauchais P., Vardelle A., Solution and suspension plasma spraying of nanostructure coatings [in] Advances plasma spray applications, H. Jazi [ed.], ISBN: 978-953-51-0349-3, InTech, 2012.

30. Sokołowski P., Pawłowski L., Review of recent studies on suspension plasma sprayed $\mathrm{ZrO} 2$ coatings [in] Advances in Materials Science Research, M.C. Wythers [ed.], 26 Nova Science Publisher, USA, 2016.

31. Curry N., VanEvery K., Snyder T., Susnjar J., Bjorklund S., Performance testing of suspension plasma sprayed thermal barrier coatings produced with varied suspension parameters, Coatings 5 (2015) 338-356.

32. Marchand O., Bertrand P., Mougin J., Comminges C., Planche M.-P., Bertrand G., Characterization of suspension plasma sprayed solid oxy fuel cells electrodes, Surface and Coatings Technology 205 (2010) 993-998.

33. Fauchais P., Etchart-Salas R., Rat V., Coudert J.F., Caron N., Wittmann-Teneze K., Parameters controlling liquid plasma spraying: solutions, sols or suspensions, Journal of Thermal Spray Technology 17 (2008) 31- 59.

34. 34.Sokołowski P., Kozerski S., Pawłowski L., Ambroziak A., The key process parameters influecing formation of columnar microstructure in suspension plasma sprayed zirconia coatings, Surface and Coatings Technology 260 (2014) 97-106.

35. Koch C.C., Synthesis of nanostructured materials by mechanical milling: problems and opportunities, Nanostructured Materials 9 (1997) 13-22.

36. Łatka L., Cattini A., Chicot D., Pawłowski L., Kozerski S., Petit F., Denoirjean A., Mechanical properties of yttria- and ceria-stabilized zirconia coatings obtained by suspension plasma spraying, Journal of Thermal Spray Technology 22 (2013) 125-130.

37. Suryanarayana C., Mechanical alloying and milling, Progress in Materials Science 46 (2001) 1184.

38. Movahedi B., Enayati M.H., Thermal spray coatings of Ni-10 wt.\% Al composite powder synthesised by low energy mechanical milling, Surface Engineering 25 (2009) 276-283.

39. Rampon R., Marchand O., Filiatre C., Bertrand G., Influence of suspension characteristics on coatings microstructure obtained by suspension plasma spraying, Surface and Coatings Technology 202 (2008) 4337-4342.

40. Toma F.-L., Bertrand G., Begin-Colin S., Meunier C., Odile B., Klein D., Coddet C., Microstructure and environmental functionalities of TiO2-supported photocatalysts obtained by suspension plasma spraying, Applied Catalysis B Environmental 68 (2006) 74-84.

41. Kassner H., Vassen R., Stoever D., Study on instant droplet and particle stages during suspension plasma spraying, Surface and Coatings Technology 202 (2008) 4355-4361.

42. Larson R.G., The structure and rheology of complex fluids, Oxford University Press, New York, 1999.

43. Mueller S., Llewellin E.W., Mader H.M., The rheology of suspensions of solid particles, Proceedings of the Royal Society A - Mathematical, Physical and Engineering Series 466 (2010) 1201-1228. 
44. Wang Z., Ni Z., Qiu D., Tao G., Yang P., Characterization of stability of ceramic suspension for slurry introduction in inductively coupled plasma optical emission spectrometry and application to aluminium nitride analysis, Journal of Analytical Atomic Spectroscopy 20 (2005) 315-319.

45. Michalak M., Łatka L., Sokołowski P., Feedstock preparation for suspension plasma spraying, Spajanie 37 (2017) 54-58 (in Polish).

46. Otterstedt J.A., Small particles technology [in] Dispersabilite, A. Foissy, S.A. Bachiri (eds.), EDP Sciences, Les Ulis, 2003.

47. Waldbillig S., Kesler O., The effect of solids and dispersant loadings on the suspension viscosities and deposition rates of suspension plasma sprayed YSZ coatings, Surface and Coatings Technology 203 (2009) 2098-2101.

48. Killinger A., Status and future trends in suspension plasma spraying [in] Future development of thermal spray coatings, N. Espallargas [ed.], Woodhead Publishing, Cambridge, 2015.

49. Hurevich V., Smurov I., Pawłowski L., Theoretical study of the powder behavior of porous particles in a flame during plasma spraying, Surface and Coatings Technology 151-152 (2002) 370-376.

50. Killinger A., Gadow R., Mauer G., Guignard A., Vassen R., Stoever D., Review of new developments in suspension and solution precursor thermal spray processes, Journal of Thermal Spray Technology 20 (2011) 677-695.

51. Fauchais P., Joulia A., Goutier S., Chazelas C., Vardelle M., Vardelle A., Rossigniol S., Suspension and solution plasma spraying, Journal of Physics D: Applied Physics 46 (2013) 114.

52. Kozerski S., Pawłowski L., Jaworski R., Roudet F., Petit F., Two zones microstructure of suspension plasma sprayed hydroxyapatite coatings, Surface and Coatings Technology 204 (2010) 1380-1387.

53. Łatka L., Goryachev S.B., Kozerski S., Pawłowski L., Sintering of fine particles in suspension plasma sprayed coatings, Materials 3 (2010) 3845-3866.

54. Łatka L., Goryachev S.B., Kozerski S., Pawłowski L., Lampke T., Buildup mechanisms of suspension plasma sprayed $\mathrm{ZrO}_{2}+8$ wt. $\% \mathrm{Y}_{2} \mathrm{O}_{3}$ coatings, Proceedings International Thermal Spray Conference, Hamburg, Germany, 2011.

55. Sokołowski P., Pawłowski L., Dietrich D., Lampke T., Jech D., Advanced microscopic study of suspension plasma sprayed zirconia coatings with different microstructures, Journal of Thermal Spray Technology 25 (2015) 94-104.

56. Pateyron B., Pawłowski L., Calve N., Delluc G., Denoirjean A., Modeling of occurring in plasma jet during suspension spraying of hydroxyapatite coatings, Surface and Coatings Technology 214 (2013) 86-90.

57. Bernard B., Quet A., Bianchi L., Joulia A., Malie A., Schick V., Remy B., Thermal insulation properties of YSZ coatings: Suspension Plasma Spraying (SPS) versus Electron Beam Physical Vapor Deposition (EB-PVD) and Atmospheric Plasma Spraying (APS), Surface and Coatings Technology 318 (2017) 122-128.

58. Sokołowski P., Nylen P., Musalek R., Łatka L., Kozerski S., Dietrich D., Lampke T., Pawłowski L., The microstructural studies of suspension plasma sprayed zirconia coatings with the use of high-energy plasma torches, Surface and Coatings Technology 318 (2017) 250-261.

59. Ganvir A., Joshi S., Markocsan N., Vassen R., Tailoring columnar microstructure of axial suspension plasma sprayed TBCs for superior thermal shock performance, Materials and Design 144 (2018) 192-208. 
60. Oliker V.E., Terent'ev A.E., Shvedova L.K., Martsenyuk I.S., Use of aqueous suspensions in plasma spraying of alumina coatings, Powder Metallurgy and Metal Ceramics 48 (2009) 115-120.

61. Tingaud O., Bertrand P., Bertrand G., Microstructure and tribological behavior of suspension plasma sprayed $\mathrm{Al}_{2} \mathrm{O}_{3}$ and $\mathrm{Al}_{2} \mathrm{O}_{3}$-YSZ composite coatings, Surface and Coatings Technology 205 (2010) 1004-1008.

62. Darut G., Valette S., Montavon G., Ageorges H., Denoirjean A., Fauchais P., Klyatskina E., Segova F., Salvador M.D., Comparison of $\mathrm{Al}_{2} \mathrm{O}_{3}$ and $\mathrm{Al}_{2} \mathrm{O}_{3}-\mathrm{TiO}_{2}$ coatings manufactured by aqueous and alcoholic suspension plasma apraying, Thermal Spray: Global Solutions for Future Application, 2010, Singapore, $\quad$ DVS Media, Dusseldorf, Germany, 2010, pp. 212-217.

63. Łatka L., Pawłowski L., Chicot D., Pierlot C., Petit F., Mechanical properties of suspension plasma sprayed hydroxyapatite coatings submitted to simulated body fluid, Surface and Coatings Technology 205 (2010) 954-960.

64. Kozerski S., Łatka L., Pawłowski L., Cernuschi F., Petit F., Pierlot C., Podlesak H., Laval J.P., Preliminary studies on suspension plasma sprayed $\mathrm{ZrO}_{2}+8$ wt. $\% \mathrm{Y}_{2} \mathrm{O}_{3}$ coatings, Journal of the European Ceramic Society 31 (2011) 2089-2098.

65. Carpio P., Bannier E., Salvador M.D., Borrell A., Moreno R., Sanchez E., Effect of particle size distribution of suspension feedstock on the microstructure and mechanical properties of suspension plasma spraying YSZ coatings, Surface and Coatings Technology, 268 (2015) 293297.

66. Zhou D., Guillon O., Vassen R., Development of YSZ thermal barrier coatings using axial suspension plasma spraying, Coatings 7 (2017) 1-17.

67. Ma X., Ruggiero P., Practical aspects of suspension plasma spray of thermal barrier coatings of potential gas turbine components, Journal of Thermal Spray Technology 27 (2018) 591-602.

68. Parker W.J., Jenkins R.J., Butler C.P., Abbot G.L., Flash method of determining thermal diffusivity, heat capacity and thermal conductivity, Journal of Applied Physics 32 (1961) 1679-1684.

69. Łatka L., Cattini A., Pawłowski L., Valette S., Pateyron B., Lecompte J.-P., Kumar R., Denoirjean A., Thermal diffusivity and conductivity of yttria stabilized zirconia coatings obtained by suspension plasma spraying, Surface and Coatings Technology 208 (2012) 87-91.

70. 70.Ganvir A., Curry N., Markocsan N., Nylen P., Toma F.-L., Comparative study of suspension plasma sprayed and suspension high velocity oxy-fuel sprayed YSZ thermal barrier coatings, Surface and Coatings Technology 268 (2015) 70-76.

71. Bernard B., Schick V., Remy B., Quet A., Bianchi L., High Temperature Thermal Properties of Columnar Yttria Stabilized Zirconia Thermal Barrier Coating Performed by Suspension Plasma Spraying, Journal of Physics: Conference Series 745 (2016).

72. Ganvir A., Curry N., Bjorklund S., Markocsan N., Nylen P., Characterization of Microstructure and Thermal Properties of YSZ Coatings Obtained by Axial Suspension Plasma Spraying (ASPS), Journal of Thermal Spray Technology 24 (2015) 1195-1204.

73. Fan W., Bai Y., Li J.R., Gao Y., Chen H.Y., Kang Y.X., Shi W.J., Li B.Q., Microstructural design and properties of supersonic suspension plasma sprayed thermal barrier coatings, Journal of Alloys and Compounds 699 (2017) 763-774.

74. Zhai M., Li D., Zhao Y., Zhong X., Shao F., Zhao H., Liu C., Tao S., Comparative study on thermal shock behavior of thick thermal barrier coatings fabricated with nano-based YSZ suspension and agglomerated particles, Ceramics International 42 (2016) 12172-12179.

75. Curry N., Tang Z., Markocsan N., Nylen P., Influence of bond coat surface roughness on the structure of axial suspension plasma spray thermal barrier coatings - thermal and lifetime performance, Surface and Coatings Technology 268 (2015) 15-23. 
76. Gupta M., Design of thermal barrier coatings, a modeling approach, Springer, London, 2015.

77. Fan W., Bai Y., Review of suspension and solution precursor plasma sprayed thermal barrier coatings, Ceramics International 42 (2016) 14299-14312.

78. Ma W., Jarligo M.O., Mack D.E., Pitzer D., Malzbender J., Vassen R., Stoever D., New generation perovskite thermal barrier coatings materials, Journal of Thermal Spray Technology 17 (2008) 831-837.

79. Habidi M.H., Wang L., Liang J., Guo S.M., An investigation on hot corrosion behavior of YSZ$\mathrm{Ta}_{2} \mathrm{O}_{5}$ in $\mathrm{Na}_{2} \mathrm{SO}_{4}+\mathrm{V}_{2} \mathrm{O}_{5}$ salt at $1100^{\circ} \mathrm{C}$, Corrosion Science 75 (2013) 409-414.

80. Mauer G., Jarligo M.O., Mack D.E., Vassen R., Plasma-sprayed thermal barrier coatings: new materials, processing issues and solutions, Journal of Thermal Spray Technology 22 (2013) 646658.

81. Cao X.Q., Vassen R., Stover D., Ceramic materials for thermal barrier coatings, Journal of the European Ceramic Society 24 (2004) 1-10.

82. Wu J., Wei X., Padture N.P., Klemens P.G., Gell M., Garcia E., Miranzo P., Osendi M.I., Low thermal conductivity rare-earth zirconates for potential thermal barrier coating applications, Journal of the American Ceramic Society 85 (2002) 3031-3035.

83. Zhu D., Miller R.A., Development of advanced low conductivity thermal barrier coatings, International Journal of Applied Ceramic Technology 1 (2004) 86-94.

84. Gong S., VanEvery K., Wang H., Trice R.W., Microstructure and thermal properties of inflight rare-earth doped thermal barriers prepared by suspension plasma spray, Journal of the European Ceramic Society 34 (2014) 1243-1253.

85. Wang C., Wang Y., Wang L., Hao G., Sun X., Shan F., Zou Z., Nanocomposite lanthanum zirconate thermal barrier coating deposited by suspension plasma spray process, Journal of Thermal Spray Technology 23 (2014) 1030-1036.

86. Vassen R., Traeger F., Stoever D., New thermal barrier coatings based on pyrochlore/YSZ double-layer systems, International Journal of Applied Ceramic Technology 1 (2004) 351-361.

87. Bakan E., Vassen R., Ceramic top coats of plasma-sprayed thermal barrier coatings: materials, processes and properties, Journal of Thermal Spray Technology 26 (2017) 992-1010.

88. Mahade S., Curry N. Bjorklund S., Markocsan N., Nylen P., Thermal conductivity and thermal cyclic fatigue of multilayered $\mathrm{Gd}_{2} \mathrm{Zr}_{2} \mathrm{O}_{7} / \mathrm{YSZ}$ thermal barrier coatings processed by suspension plasma spray, Surface and Coatings Technology 283 (2015) 329-336.

89. 89.Mahade S., Curry N. Bjorklund S., Markocsan N., Nylen P., Vassen R., Functional performances of $\mathrm{Gd}_{2} \mathrm{Zr}_{2} \mathrm{O}_{7} / \mathrm{YSZ}$ multi-layered thermal barrier coatings deposited by suspension plasma spray, Surface and Coatings Technology 318 (2017) 208-216.

90. Schlegel N., Sebold D., Sohn Y.J., Mauer G., Vassen R., Cycling performance of a columnarstructured complex perovskite in a temperature gradient test, Journal of Thermal Spray Technology 24 (2015) 1205-1212.

91. Wang C., Wang Y., Fan S., You Y., Wang L., Yang C., Sun X., Li X., Optimized functionally graded $\mathrm{La}_{2} \mathrm{Zr}_{2} \mathrm{O}_{7} / 8 \mathrm{YSZ}$ thermal barrier coatings fabricated by suspension plasma spraying, Journal of Alloys and Compounds 649 (2015) 1182-1190.

92. Mahade S., Curry N. Bjorklund S., Markocsan N., Nylen P., Engineered thermal barrier coatings deposited by suspension plasma spray, Materials Letters 209 (2017) 517-521.

93. Carpio P., Salvador M.D., Borrel A., Navarro L., Sanchez E., Molten salt attack on multilayer and functionally-graded YSZ coatings, Ceramic International 44 (2018) 12634-12641.

94. Curry N., Design of thermal barrier coatings, PhD Thesis, University West, Sweden, 2014. 